University of Wollongong

Research Online

Faculty of Science - Papers (Archive)

Faculty of Science, Medicine and Health

2012

\title{
Atmospheric carbon dioxide retrieved from the Greenhouse gases Observing SATellite (GOSAT): Comparison with ground-based TCCON observations and GEOS-Chem model calculations
}

\author{
A Cogan \\ University of Leicester \\ H Boesch \\ University of Leicester \\ R Parker \\ University of Leicester \\ L Feng \\ University of Edinburgh \\ Paul Palmer \\ University of Edinburgh, pip@ed.ac.uk
}

See next page for additional authors

Follow this and additional works at: https://ro.uow.edu.au/scipapers

Part of the Life Sciences Commons, Physical Sciences and Mathematics Commons, and the Social and Behavioral Sciences Commons

\section{Recommended Citation}

Cogan, A; Boesch, H; Parker, R; Feng, L; Palmer, Paul; Blavier, J-F; Deutscher, Nicholas M.; Macatangay, Ronald; Notholt, Justus; Roehl, C M.; Warneke, Thorsten; and Wunch, Debra: Atmospheric carbon dioxide retrieved from the Greenhouse gases Observing SATellite (GOSAT): Comparison with ground-based TCCON observations and GEOS-Chem model calculations 2012.

https://ro.uow.edu.au/scipapers/4708

Research Online is the open access institutional repository for the University of Wollongong. For further information contact the UOW Library: research-pubs@uow.edu.au 


\title{
Atmospheric carbon dioxide retrieved from the Greenhouse gases Observing SATellite (GOSAT): Comparison with ground-based TCCON observations and GEOS-Chem model calculations
}

\begin{abstract}
We retrieved column-averaged dry air mole fractions of atmospheric carbon dioxide (XCO 2) from backscattered short-wave infrared (SWIR) sunlight measured by the Japanese Greenhouse gases Observing SATellite (GOSAT). Over two years of XCO 2 retrieved from GOSAT is compared with XCO 2 inferred from collocated SWIR measurements by seven ground-based Total Carbon Column Observing Network (TCCON) stations. The average difference between GOSAT and TCCON XCO 2 for individual TCCON sites ranges from $-0.87 \mathrm{ppm}$ to $0.77 \mathrm{ppm}$ with a mean value of $0.1 \mathrm{ppm}$ and standard deviation of $0.56 \mathrm{ppm}$. We find an average bias between all GOSAT and TCCON XCO 2 retrievals of $-0.20 \mathrm{ppm}$ with a standard deviation of $2.26 \mathrm{ppm}$ and a correlation coefficient of 0.75 . One year of XCO 2 was retrieved from GOSAT globally, which was compared to global 3-D GEOS-Chem chemistry transport model calculations. We find that the latitudinal gradient, seasonal cycles, and spatial variability of GOSAT and GEOS-Chem agree well in general with a correlation coefficient of 0.61. Regional differences between GEOS-Chem model calculations and GOSAT observations are typically less than $1 \mathrm{ppm}$ except for the Sahara and central Asia where a mean difference between 2 to $3 \mathrm{ppm}$ is observed, indicating regional biases in the GOSAT XCO 2 retrievals unobserved by the current TCCON network. Using a bias correction scheme based on linear regression these regional biases are significantly reduced, approaching the required accuracy for surface flux inversions. 2012. American Geophysical Union.
\end{abstract}

\section{Keywords}

calculations, dioxide, retrieved, greenhouse, gases, observing, satellite, gosat, comparison, ground, carbon, tccon, atmospheric, observations, geos, chem, model, GeoQUEST

\section{Disciplines}

Life Sciences | Physical Sciences and Mathematics | Social and Behavioral Sciences

\section{Publication Details}

Cogan, A., Boesch, H., Parker, R., Feng, L., Palmer, P., Blavier, J., Deutscher, N. M., Macatangay, R., Notholt, J., Roehl, C. M., Warneke, T. \& Wunch, D. (2012). Atmospheric carbon dioxide retrieved from the Greenhouse gases Observing SATellite (GOSAT): Comparison with ground-based TCCON observations and GEOS-Chem model calculations. Journal of Geophysical Research D: Atmospheres, 117 (21), D21301.

Authors

A Cogan, H Boesch, R Parker, L Feng, Paul Palmer, J-F Blavier, Nicholas M. Deutscher, Ronald Macatangay, Justus Notholt, C M. Roehl, Thorsten Warneke, and Debra Wunch 


\title{
Atmospheric carbon dioxide retrieved from the Greenhouse gases Observing SATellite (GOSAT): Comparison with ground-based TCCON observations and GEOS-Chem model calculations
}

\author{
A. J. Cogan, ${ }^{1}$ H. Boesch, ${ }^{1}$ R. J. Parker, ${ }^{1}$ L. Feng, ${ }^{2}$ P. I. Palmer, ${ }^{2}$ J.-F. L. Blavier, ${ }^{3}$ \\ N. M. Deutscher, ${ }^{4}$ R. Macatangay, ${ }^{5}$ J. Notholt ${ }^{4}$ C. Roehl, ${ }^{3}$ T. Warneke, ${ }^{4}$ and D. Wunch ${ }^{3}$ \\ Received 8 May 2012; revised 17 September 2012; accepted 21 September 2012; published 1 November 2012.
}

[1] We retrieved column-averaged dry air mole fractions of atmospheric carbon dioxide $\left(\mathrm{X}_{\mathrm{CO}_{2}}\right)$ from backscattered short-wave infrared (SWIR) sunlight measured by the Japanese Greenhouse gases Observing SATellite (GOSAT). Over two years of $\mathrm{X}_{\mathrm{CO}_{2}}$ retrieved from GOSAT is compared with $\mathrm{X}_{\mathrm{CO}_{2}}$ inferred from collocated SWIR measurements by seven ground-based Total Carbon Column Observing Network (TCCON) stations. The average difference between GOSAT and TCCON $\mathrm{X}_{\mathrm{CO}_{2}}$ for individual TCCON sites ranges from $-0.87 \mathrm{ppm}$ to $0.77 \mathrm{ppm}$ with a mean value of $0.1 \mathrm{ppm}$ and standard deviation of $0.56 \mathrm{ppm}$. We find an average bias between all GOSAT and TCCON X $\mathrm{CO}_{2}$ retrievals of $-0.20 \mathrm{ppm}$ with a standard deviation of $2.26 \mathrm{ppm}$ and a correlation coefficient of 0.75. One year of $\mathrm{X}_{\mathrm{CO}_{2}}$ was retrieved from GOSAT globally, which was compared to global 3-D GEOS-Chem chemistry transport model calculations. We find that the latitudinal gradient, seasonal cycles, and spatial variability of GOSAT and GEOS-Chem agree well in general with a correlation coefficient of 0.61 . Regional differences between GEOS-Chem model calculations and GOSAT observations are typically less than $1 \mathrm{ppm}$ except for the Sahara and central Asia where a mean difference between 2 to $3 \mathrm{ppm}$ is observed, indicating regional biases in the GOSAT $\mathrm{X}_{\mathrm{CO}_{2}}$ retrievals unobserved by the current TCCON network. Using a bias correction scheme based on linear regression these regional biases are significantly reduced, approaching the required accuracy for surface flux inversions.

Citation: Cogan, A. J., et al. (2012), Atmospheric carbon dioxide retrieved from the Greenhouse gases Observing SATellite (GOSAT): Comparison with ground-based TCCON observations and GEOS-Chem model calculations, J. Geophys. Res., 117, D21301, doi:10.1029/2012JD018087.

\section{Introduction}

[2] Carbon dioxide $\left(\mathrm{CO}_{2}\right)$ is the dominant anthropogenic greenhouse gas and its atmospheric concentration has dramatically increased from a pre-industrial level of $280 \mathrm{ppm}$ to a current value of about 390 ppm as a consequence of human

\footnotetext{
${ }^{1}$ Earth Observation Science, Space Research Centre, Department of Physics and Astronomy, University of Leicester, Leicester, UK.

${ }^{2}$ School of GeoSciences, University of Edinburgh, Edinburgh, UK.

${ }^{3}$ Division of Geological and Planetary Sciences, California Institute of Technology, Pasadena, California, USA.

${ }^{4}$ Institute of Environmental Physics, Institute of Remote Sensing, University of Bremen, Bremen, Germany.

${ }^{5}$ Centre for Atmospheric Chemistry, School of Chemistry, University of Wollongong, Wollongong, New South Wales, Australia.

Corresponding author: A. J. Cogan, Earth Observation Science, Space Research Centre, Department of Physics and Astronomy, University of Leicester, Leicester LE1 7RH, UK. (ajc48@le.ac.uk)

C2012. American Geophysical Union. All Rights Reserved. 0148-0227/12/2012JD018087
}

activities such as burning of fossil fuels or deforestation [Intergovernmental Panel on Climate Change (IPCC), 2007; Masarie and Tans, 1995]. This increase in $\mathrm{CO}_{2}$ concentrations is responsible for a change in global mean radiative forcing of $1.66 \mathrm{Wm}^{-2}$ [IPCC, 2007] and it is expected that further increasing $\mathrm{CO}_{2}$ concentrations will significantly alter our climate in the future [IPCC, 2001].

[3] Networks of surface in situ greenhouse gas sensors provide precise and accurate measurements of $\mathrm{CO}_{2}$ concentrations. These measurements allow the quantification of large scale temporal, seasonal and latitudinal variations in $\mathrm{CO}_{2}$. However, their sparse and uneven global distribution results in large uncertainties in the natural carbon cycle for key regions such as tropical or boreal regions [Hungershoefer et al., 2010; Gurney et al., 2002].

[4] As shown by numerous synthetic studies, denselysampled satellite observations of $\mathrm{CO}_{2}$ concentrations can help to reduce uncertainties in estimated regional carbon fluxes if the observations have precisions of 1-2 ppm on a regional scale with no regional to continental scale geographical biases [Rayner and O'Brien, 2001; Houweling 
et al., 2004; Chevallier, 2007; Miller et al., 2007; Feng et al., 2009; Baker et al., 2010; Hungershoefer et al., 2010; Palmer et al., 2011]. However, Palmer et al. [2011] found that the benefit of the increased number of soundings of satellite observations is reduced with more correlated data.

[5] Satellite observations of short-wave infrared (SWIR) $\mathrm{CO}_{2}$ absorption bands are well suited for constraining surface fluxes as they provide observations of column averaged dry air mole fraction of $\mathrm{CO}_{2}\left(\mathrm{X}_{\mathrm{CO}_{2}}\right)$ with high precision and sensitivity to the planetary boundary layer [Boesch et al., 2011; Christi and Stephens, 2004; Kuang et al., 2002]. The use of SWIR measurements for retrievals of $\mathrm{X}_{\mathrm{CO}_{2}}$ from space was demonstrated for the first time with the SCanning Imaging Absorption spectroMeter for Atmospheric CHartographY (SCIAMACHY) instrument onboard the ENVISAT satellite, which achieved precisions of 1-2\% [Barkley et al., 2006; Buchwitz et al., 2005; Reuter et al., 2010; Schneising et al., 2008].

[6] The first dedicated greenhouse gas mission was launched in January 2009 by JAXA on a H-IIA rocket with the Greenhouse gases Observing SATellite (GOSAT) onboard it [Kuze et al., 2009]. GOSAT contains the Thermal And Near-infrared Sensor for carbon Observation (TANSO) that comprises of two instruments; a Fourier Transform Spectrometer (FTS) and a Cloud and Aerosol Imager (CAI) that provides information about the scene, such as cloud quantities. The TANSO-FTS sensor measures radiance spectrain three SWIR bands between $0.756-0.775 \mu \mathrm{m}, 1.56-1.72 \mu \mathrm{m}$ and $1.92-2.08 \mu \mathrm{m}$, and in one thermal infrared (TIR) band between 5.6-14.3 $\mu \mathrm{m}$ with spectral resolutions between $0.257-0.367 \mathrm{~cm}^{-1}$ [Kuze et al., 2009]. TANSO-FTS applies gain (low, medium or high) to the SWIR signals to amplify the signals to an appropriate voltage to compensate for high and low observed intensities. Additionally, it measures each polarization direction separately.

[7] TANSO-FTS nominally performs a cross-track scanning pattern with an instantaneous field of view (IFOV) of $15.8 \mathrm{mrad}$, equivalent to $\sim 10.5 \mathrm{~km}$ diameter projected on to the Earth's surface. Until August 2010, the standard mode consisted of five cross-track points separated by $\sim 158 \mathrm{~km}$. This has since been changed to three points to reduce pointing errors caused by micro-vibrations which are most extreme at the largest off-nadir pointing angles [Crisp et al., 2012]. Additionally, TANSO-FTS can measure in sun-glint mode within $20^{\circ}$ of the sub-solar latitude and in specific observation mode that provides targeted observations for validation.

[8] Results of $\mathrm{X}_{\mathrm{CO}_{2}}$ retrieved from GOSAT have previously been reported by other groups [Oshchepkov et al., 2009; Yokota et al., 2009; Butz et al., 2011; Morino et al., 2011; Wunch et al., 2011b; Yoshida et al., 2011; Crisp et al., 2012; Oshchepkov et al., 2012]. These include comparisons to ground-based measurements, global comparisons to model calculations and methods towards improving the retrieved $\mathrm{X}_{\mathrm{CO}_{2}}$ precision.

[9] We describe our optimal estimation retrieval approach used to retrieve $\mathrm{X}_{\mathrm{CO}_{2}}$ from GOSAT in Section 2. We compare these retrievals with coincident ground-based $\mathrm{X}_{\mathrm{CO}_{2}}$ observations (Section 3 ) and to model calculations (Section 4). A bias correction scheme and its impact on $\mathrm{X}_{\mathrm{CO}_{2}}$ retrieved from
GOSAT is discussed in Section 5, and in Section 6 we conclude the paper.

\section{UoL-FP $\mathrm{X}_{\mathrm{CO}_{2}}$ Retrieval Algorithm}

[10] The University of Leicester Full Physics (UoL-FP) retrieval utilizes the algorithm developed for the NASA Orbiting Carbon Observation (OCO) mission [Boesch et al., 2006, 2011; Connor et al., 2008; Crisp et al., 2004; Parker et al., 2011], which was lost due to a launch vehicle malfunction [Boesch et al., 2011]. The UoL-FP algorithm and the algorithm used for the NASA Atmospheric $\mathrm{CO}_{2}$ Observations from Space (ACOS) project and the NASA OCO-2 mission [Crisp et al., 2012; O'Dell et al., 2012], are two parallel developments based on the OCO algorithm and thus both algorithms follow a similar retrieval strategy. While the UoL-FP algorithm utilizes the OCO algorithm, the ACOS algorithm is a re-development of it such that the implementation of both algorithms are independent of each other. Both retrieval algorithms differ in their definition of the state vector, a priori values, and a priori covariances, especially in the treatment of aerosols and cirrus clouds. There are also differences in spectroscopy, sounding selection methods, and postscreening criteria. All of these aspects can lead to differences in algorithm performance and $\mathrm{X}_{\mathrm{CO} 2}$.

[11] The algorithm has been designed to retrieve $\mathrm{X}_{\mathrm{CO}_{2}}$ from SWIR spectra by simultaneously fitting the $0.76 \mu \mathrm{m} \mathrm{O}_{2} \mathrm{~A}$ band, the $1.61 \mu \mathrm{m}$ and the $2.06 \mu \mathrm{m} \mathrm{CO}_{2}$ bands [Boesch et al., 2006, 2011; Connor et al., 2008]. The algorithm employs an inverse method, where an iterative retrieval system based on Bayesian optimal estimation (maximum likelihood estimation) fits the simulated spectral radiance to the measured spectral radiance in order to infer $\mathrm{X}_{\mathrm{CO}_{2}}$ [Rodgers, 2000]. The $\mathrm{OCO}$ algorithm has been altered to perform retrievals of $\mathrm{X}_{\mathrm{CO}_{2}}$ by simultaneously fitting the GOSAT SWIR bands, using the wavelength ranges of $0.758-0.772 \mu \mathrm{m}, 1.588-1.623 \mu \mathrm{m}$, and 2.040-2.083 $\mu \mathrm{m}$.

[12] The forward model that simulated the measured spectra includes solar, radiative transfer, and instrument models to simulate the spectral radiance of a scene. We use the lowstreams interpolation functionality [O'Dell, 2010] to accelerate the LIDORT radiative transfer model [Spurr et al., 2001], which is combined with a fast 2-orders-of-scattering vector radiative transfer code [Natraj and Spurr, 2007].

[13] The state vector gives the retrieved parameters and consists of a 20-level profile of $\mathrm{CO}_{2}$ volume mixing ratio (VMR) and 20-level logarithmic extinction profiles of cirrus and two aerosol types. In addition, the state vector includes multiplicative scaling factors for $\mathrm{CH}_{4} \mathrm{VMR}$ and $\mathrm{H}_{2} \mathrm{O}$ VMR, an additive offset for a temperature profile, surface pressure, surface albedo, spectral albedo slope, and spectral shift/stretch. We also retrieve an additive $\mathrm{O}_{2} \mathrm{~A}$ band intensity offset to mitigate the effects of fluorescence and the GOSAT Band 1 non-linear response to the intensity of incident radiation, that is currently being characterized and calibrated [Crisp et al., 2012; Frankenberg et al., 2011; Suto et al., 2011].

[14] The a priori temperature and water vapor profiles and surface pressure were obtained from the European Centre for Medium-Range Weather Forecasts (ECMWF) Operational Analyses data interpolated to the location and time of each 
Table 1. Threshold Values for Parameters Used in Postscreening the UoL-FP Retrieval Algorithm v3G

\begin{tabular}{lcc}
\hline \multicolumn{1}{c}{ Parameter } & Lower Limit & Upper Limit \\
\hline Retrieval convergence outcome & 1 & 2 \\
$\chi^{2}$ Band 1 & 0.6 & 1.3 \\
$\chi^{2}$ Band 2 & 0.6 & 1.5 \\
$\chi^{2}$ Band 3 & 0.4 & 1.5 \\
A Posterior Error (ppm) & 0 & 1.6 \\
Retrieved - A priori surface & & 16 \\
$\quad$ pressure (hPa) & & 0.3 \\
Retrieved aerosol 1 optical depth & & 0.4 \\
Retrieved aerosol 2 optical depth & & $0.05,0.03^{\mathrm{a}}$ \\
Retrieved ice optical depth & & $0.5,0.3^{\mathrm{a}}$ \\
Retrieved total optical depth & & 0 \\
8-11 $\mu$ m Brightness Temperature & & 2 \\
$\quad$ Difference & & 1.05 \\
Number of divergences & -2 & \\
Cirrus test & 0.7 & 1.3 \\
Retrieved temperature scale (K) & -0.022 & 0.022 \\
Retrieved H ${ }_{2}$ O scale factor & & \\
Retrieved - A priori band 2 spectral & -0.002 & 0.0014 \\
$\quad$ shift (cm ${ }^{-1}$ ) & & $4,2^{\mathrm{a}}$ \\
Retrieved band 1 zero level offset & & \\
Retrieved albedo band 1/band 3 & & \\
\hline
\end{tabular}

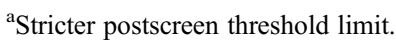

GOSAT sounding, with corrections for altitude. The a priori information for the $\mathrm{CH}_{4}$ profile was taken from the TM3 model provided by $\mathrm{S}$. Houweling (personal communication, 2009). The a priori $\mathrm{CO}_{2}$ profiles were obtained from 2009 fields of the Laboratory of Climate Sciences and Environment (LCSE) General Circulation Model of Laboratoire de Meteorologie Dynamique (LMDZ) [Pickett-Heaps et al., 2011]. A correction of $18.25 \mathrm{ppm}$ was applied to the 2009 $\mathrm{CO}_{2}$ profiles that was derived from a comparison with National Oceanic and Atmospheric Administration (NOAA) observations over Mauna Loa. Additionally, yearly increments of $1.63 \mathrm{ppm}$ and $2.36 \mathrm{ppm}$ were taken from global NOAA observations [Masarie and Tans, 1995] and applied to the $\mathrm{CO}_{2}$ profiles for 2010 and 2011 respectively, to account for increasing atmospheric $\mathrm{CO}_{2}$ concentrations. The albedo a priori was inferred using the reflectance of the measured radiance at continuum wavelengths of each band. The spectral dispersion a priori was calculated by comparing the measured radiance to the position of a known solar line at $12985.163 \mathrm{~cm}^{-1}$.

[15] The a priori aerosol profiles are both set up as a Gaussian-shaped aerosol extinction profile with a height and width of $2 \mathrm{~km}$. The aerosol optical properties for the two aerosol types that are used to describe the unknown scenedependent aerosol are calculated for carbonaceous/dusty continental and carbonaceous/sooty continental aerosol mixtures described in Kahn et al. [2001], where the optical properties of spherical aerosol particles were computed using a polydisperse Mie scattering code [de Rooij and van der Stap, 1984] and non-spherical aerosol particles were computed using a T-matrix code [Mishchenko and Travis, 1998]. A Gaussian-shaped extinction profile with latitudinal dependent height and width based on Eguchi et al. [2007] was used for the cirrus profile. The cirrus optical properties were taken from the Baum model [Baum et al., 2005] for non-spherical ice particles with an effective radius of $60 \mu \mathrm{m}$. A total optical depth of 0.15 was used globally, with each aerosol/cirrus profile having a total column optical depth of 0.05 at the $\mathrm{O}_{2}$ A Band.

[16] For all retrievals we use a single a priori covariance matrix with a column variability of $12 \mathrm{ppm}$ for $\mathrm{CO}_{2}$ (based on global estimates of Dufour and Breon [2003]) that decreases with altitude, from an uncertainty of $\sim 10 \%$ at the boundary layer to $\sim 1 \%$ in the stratosphere. For the surface pressure we use a standard deviation of $4 \mathrm{hPa}$ to allow for more difficult topographies. To account sufficiently for the expected large variability of aerosols and cirrus clouds, we use a standard deviation with a factor of 50 for each atmospheric level. A standard deviation of 0.32 is used for both $\mathrm{CH}_{4}$ and $\mathrm{H}_{2} \mathrm{O}$ scale factors. For the temperature offset we use a standard deviation of $3.2 \mathrm{~K}$. We use a standard deviation of 1 for albedo and standard deviation of $0.01 \mathrm{~cm}^{-1}$ for albedo slope of each band.

[17] The retrieval utilizes tabulated spectroscopic parameters for each trace gas; $\mathrm{CO}_{2}$ and $\mathrm{O}_{2}$ include line-mixing and are taken from v3.2 of the OCO line-lists [Crisp et al., 2012], whereas $\mathrm{CH}_{4}$ and $\mathrm{H}_{2} \mathrm{O}$ are from the TCCON linelists (Geoffrey Toon, personal communication, 2011). These are based on HITRAN08 [Rothman et al., 2009] with updates to $\mathrm{CO}_{2}$ [Toth, 2005], $\mathrm{H}_{2} \mathrm{O}$ [Toth et al., 2008; Jenouvrier et al., 2007] and $\mathrm{CH}_{4}$ [Frankenberg et al., 2008].

[18] We apply the recommended radiometric calibration and solar diffuser degradation correction to the latest versions of the GOSAT Level 1B files $(050.050 \mathrm{C}, 080.080 \mathrm{C}, 100.100 \mathrm{C}$, $110.110 \mathrm{C}$ and $130.130 \mathrm{C}$ ) acquired via the GOSAT User Interface Gateway. We calculate the noise from the standard deviation of the out-of-band signal and approximate the measured radiance by taking the average of the polarized intensities.

[19] We only use spectra over land with a solar zenith angle less than $70^{\circ}$ and signal-to-noise ratio higher than 50 in each band. We also prescreen for non-saturated measurements using mean band 2 out-of-band radiances $<3.5 \times 10^{-5}$ and mitigate the effects of micro-vibrations [Suto et al., 2011] by limiting the along-track and cross-track angle errors to within 3 -sigma values (inferred from August 2009) of $<0.05^{\circ}$ and $<0.007^{\circ}$ respectively, such that large pointing errors are removed. Additionally, we calculate the surface pressure for all locations where U.S. Geological Survey (USGS) GTOPO30 altitude information exists within an IFOV ( 60 points), and screen for areas of large surface variations where the surface pressure may vary significantly, using a standard deviation threshold of $<10 \mathrm{hPa}$.

[20] Similar to Taylor et al. [2012], we use a cloud detection method based on the difference between retrieved clearsky surface pressure from an $\mathrm{O}_{2} \mathrm{~A}$ band retrieval and surface pressure from ECMWF interpolated to the location and time, where the maximum difference allowed is $20 \mathrm{hPa}$ [Parker et al., 2011]. Our approach uses only a small spectral window (13056 to $13074.8 \mathrm{~cm}^{-1}$ ) where the $\mathrm{O}_{2} \mathrm{~A}$ band absorption shows only a weak dependence on temperature.

[21] We apply a number of postscreening criteria to the successful retrievals to reduce the scatter and to remove problematic and potentially biased retrievals. An overview of the empirically derived postscreening criteria is shown in Table 1, with its application shown for a combination of seven TCCON sites (see Section 3) over a two year period in 


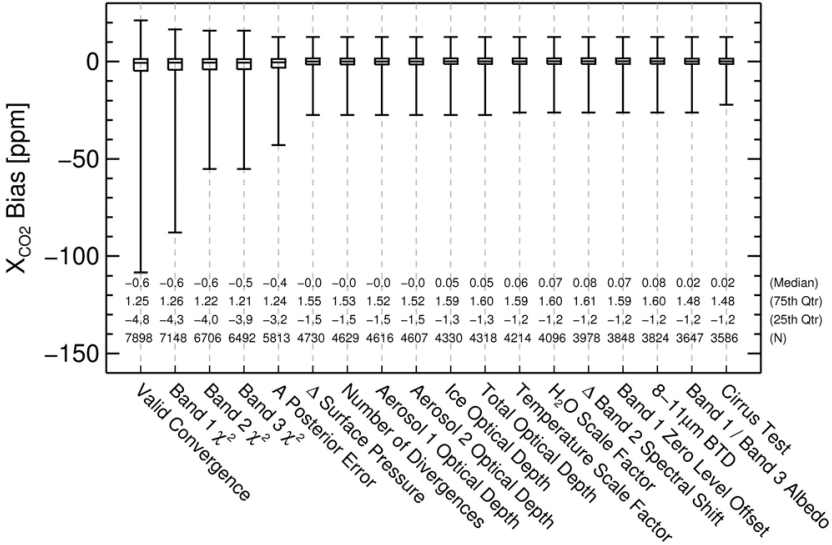

Figure 1. Box-whisker plot of $\mathrm{X}_{\mathrm{CO}_{2}}$ retrieved from GOSAT for seven TCCON sites combined between April 2009 and May 2011. The effect of each postscreen parameter is shown sequentially along the $\mathrm{x}$-axis.

Figure 1. The post screen threshold values were inferred from correlations of various parameters with the $\mathrm{X}_{\mathrm{CO}_{2}}$ bias between GOSAT and TCCON for coincident observations over Lamont/USA and Darwin/Australia (see Section 3) and by considering the distribution and scatter of global $\mathrm{X}_{\mathrm{CO}_{2}}$ data retrieved for August 2009. The postscreen selects only converged retrievals with a good spectral fit (where the normalized $\chi^{2}$ of the fit residual is $\sim 1$ ) and a low posterior error of $\mathrm{X}_{\mathrm{CO}_{2}}(<1.6 \mathrm{ppm})$. In addition, we also filter for a number of parameters related to thin clouds and aerosols, which include: the difference between retrieved and ECMWF surface pressure $(0-16 \mathrm{hPa})$, the retrieved cirrus optical depth $(<0.05)$, the band 4 (TIR) brightness temperature difference (BTD) between $8 \mu \mathrm{m}$ and $11 \mu \mathrm{m}$ (where $>0$ indicates cloud/cirrus), a test for cirrus based on the radiance ratio of $2.1038 \mu \mathrm{m}$ to $2.0906 \mu \mathrm{m}$ (where cirrus absorption occurs below a value of 0.98 ), and the ratio of $0.76 \mu \mathrm{m}$ to $2.06 \mu \mathrm{m}$ albedo that indicates ice/snow if the value is $>4$. Scenes containing a large retrieved aerosol amount (AOD $>0.5$ ) are also removed. We also find correlations of temperature and water vapor scale factors have an affect with the $\mathrm{X}_{\mathrm{CO}_{2}}$ bias; therefore we remove cases where these have clear outliers, which indicates a poor retrieval.
[22] On average, we observed a bias in retrieved surface pressure of $\sim 4 \mathrm{hPa}$, which is lower than reported by Crisp et al. [2012]. This bias has been suggested to be due to deficiencies in the $\mathrm{O}_{2}$ A band spectroscopy and that scaling the line strength of $\mathrm{O}_{2}$ could reduce it [Butz et al., 2011]. For our retrieval, instead of scaling the line strength, we correct for the systematic overestimates of surface pressure by normalizing the retrieved $\mathrm{X}_{\mathrm{CO}_{2}}$ with the ratio of retrieved surface pressure and ECMWF surface pressure.

[23] A total of 1,718,561 GOSAT observations globally over land between June 2009 and May 2010 have been processed, reducing to 764,290 scenes $(44.47 \%)$ once prescreened. These were then cloud-screened, leaving 372,479 scenes $(21.67 \%)$ to be retrieved, which reduced to a total of $62,278(3.62 \%)$ retrievals of $\mathrm{X}_{\mathrm{CO}_{2}}$ once postscreened. Details of this are given in Table 2. Additionally, we processed a total of 172,193 GOSAT observations over land for seven sites of the Total Carbon Column Observing Network (TCCON) between April 2009 and May 2011. Once prescreened, cloud-screened and postscreened 5,860 (3.40\%) observations remained, details of which can be found in Table 3 .

\section{Comparison With the Total Carbon Column Observing Network (TCCON)}

[24] The Total Carbon Column Observing Network (TCCON) is a network of ground-based, solar absorption, near infrared, Fourier transform spectrometers that measure atmospheric columns of the gases $\mathrm{CO}_{2}, \mathrm{CO}, \mathrm{CH}_{4}, \mathrm{H}_{2} \mathrm{O}$ and others with a precision of $0.25 \%$ for $\mathrm{CO}_{2}$ [Wunch et al., 2010, 2011a], making it an ideal data set for validation of retrieved $\mathrm{X}_{\mathrm{CO}_{2}}$ from GOSAT. Since the TCCON instruments are direct solar-viewing, the effects of aerosol and high cirrus cloud are negligible. To maintain consistency between different TCCON observatories, all sites use the same instrumentation and the same software for data processing and analysis. This includes the conversion of raw interferograms into spectra, which are then spectrally fitted using the GFIT algorithm with subsequent quality controls applied to the column abundances [Wunch et al., 2011a]. Wunch et al. [2010] compared the retrieved $\mathrm{X}_{\mathrm{CO}_{2}}$ from TCCON with aircraft observations using 14 coincident profiles and found that a single, global calibration factor of 0.989 accurately matches the data within the error. Subsequently, Messerschmidt et al.

Table 2. UoL-FP v3G Retrieval Statistics for 1 Year of Daytime, Land Only Global GOSAT Observations

\begin{tabular}{|c|c|c|c|c|c|c|c|}
\hline Year Month & Total From L1B & Passed Prescreen & $\mathrm{O}_{2}$ Completed & Cloudy Exposures & Clear Exposures & Retrieval Completed & Passed Postscreen \\
\hline 200906 & 126745 & 55303 & 51768 & 27863 & 23905 & 22881 & 5724 \\
\hline 200907 & 139663 & 61514 & 57799 & 31098 & 26701 & 25660 & 7474 \\
\hline 200908 & 139615 & 60201 & 56234 & 30330 & 25904 & 24928 & 7306 \\
\hline 200909 & 141572 & 62622 & 56988 & 29217 & 27771 & 27012 & 6761 \\
\hline 200910 & 150659 & 70907 & 63121 & 27433 & 35688 & 34135 & 6197 \\
\hline 200911 & 146340 & 72724 & 64645 & 24510 & 40135 & 37844 & 4563 \\
\hline 200912 & 149908 & 74701 & 67443 & 24562 & 42881 & 39356 & 4358 \\
\hline 201001 & 146740 & 65452 & 58947 & 23001 & 35946 & 33295 & 4213 \\
\hline 201002 & 145925 & 62328 & 56048 & 24161 & 31887 & 30089 & 3492 \\
\hline 201003 & 158284 & 64685 & 59158 & 27064 & 32094 & 30811 & 3691 \\
\hline 201004 & 138638 & 55586 & 50783 & 26310 & 24473 & 23207 & 3484 \\
\hline 201005 & 134472 & 58267 & 54104 & 29010 & 25094 & 23719 & 5015 \\
\hline Total & 1718561 & 764290 & 697038 & 324559 & 372479 & 352937 & 62278 \\
\hline
\end{tabular}


[2011] found additional European TCCON sites to be consistent with this calibration factor. Additionally, an air mass dependent correction factor was applied as described in Wunch et al. [2011a].

[25] We performed $\mathrm{X}_{\mathrm{CO}_{2}}$ retrievals from GOSAT between April 2009 and May 2011 over seven TCCON sites; Lamont/ USA, Park Falls/USA, Orleans/France, Bialystok/Poland, Bremen/Germany, Darwin/Australia and Wollongong/ Australia. These sites were selected to provide northern and southern hemispheric data with at least 200 GOSAT soundings per site. We use all prescreened, cloudscreened and postscreened GOSAT measurements over land within a coincidence criteria of $5^{\circ}$ of each TCCON site and \pm 2 hours of TCCON observations. The coincidence criteria is a compromise between a sufficient number of soundings and the spatial distance from a TCCON site.

[26] Figure 2 shows a comparison of the retrieved $\mathrm{X}_{\mathrm{CO}_{2}}$ from GOSAT with coincident TCCON $\mathrm{X}_{\mathrm{CO}_{2}}$ data for these seven TCCON sites (without averaging kernels applied). It also shows the correlation of coincident daily mean GOSAT $\mathrm{X}_{\mathrm{CO}_{2}}$ with the average of all TCCON X $\mathrm{CO}_{2}$ within \pm 2 hours of coincident GOSAT data. We observe the GOSAT $\mathrm{X}_{\mathrm{CO}_{2}}$ to have values consistent with TCCON retrievals for all sites for the entire time period and find a very good agreement between coincident data. In particular we find the seasonal cycle observed for northern hemispheric sites is well reproduced by GOSAT with correlation coefficients between 0.56 and 0.85 , similar to that observed by Butz et al. [2011], Oshchepkov et al. [2012], and Wunch et al. [2011b]. Consistent to the TCCON measurements, the two southern hemisphere sites, Darwin and Wollongong, show weaker seasonal cycles than the northern hemisphere sites. However, we find the retrieved $\mathrm{X}_{\mathrm{CO}_{2}}$ from GOSAT over Wollongong to have a slightly enhanced seasonal cycle.

[27] Gaps exist in the GOSAT and TCCON time-series due to clouds and instrumental issues. The number of points per site varies mainly due to seasonal cloud cover and the number of overpassing orbits. The number of soundings of each station varies from 260 for Bremen to 2445 for Lamont, with the number of coincident days with TCCON between 19 and 261 , respectively. The Lamont site has the largest sample size due to multiple orbit overpasses within the coincidence criteria and less clouds than the other sites at higher absolute latitudes.

[28] Using the data for all sites (Figure 2, bottom right) we calculate the average bias of GOSAT compared to TCCON as $-0.20 \mathrm{ppm}$ with a standard deviation of $2.26 \mathrm{ppm}$ (using daily means), which is similar to that found by Butz et al. [2011] and lower than reported by other algorithms [e.g., Crisp et al., 2012; Morino et al., 2011; Oshchepkov et al., 2012]. Using single soundings instead of daily means, we find a standard deviation of $2.46 \mathrm{ppm}$. The average of the bias per station is $0.10 \mathrm{ppm}$ with a range of -0.87 to $0.77 \mathrm{ppm}$ and a standard deviation of $0.56 \mathrm{ppm}$ (using daily mean data). We find the mean correlation coefficient between GOSAT and TCCON observations to be 0.75 . The mean bias and scatter are largely influenced by the large number of soundings over the Lamont site. The highest scatter is observed for Bremen, which has the lowest number of scenes (see Table 3 for details).

[29] The standard deviation of the retrieved $\mathrm{X}_{\mathrm{CO}_{2}}$ inferred from comparisons to coincident TCCON data is substantially 


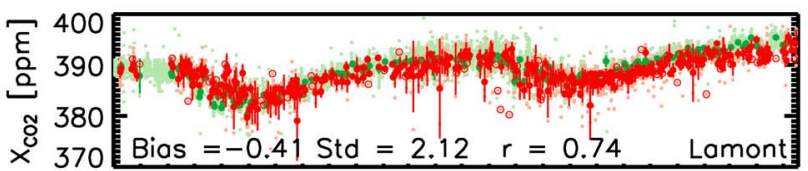

$A M J J A S O N D J F M A M J J A S O N D J F M A M$ Month of Year (2009-2011)

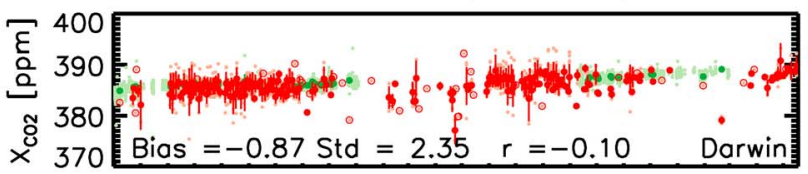

$A M J J A S O N D J F M A M J J A S O N D J F M A M$ Month of Year (2009-2011)

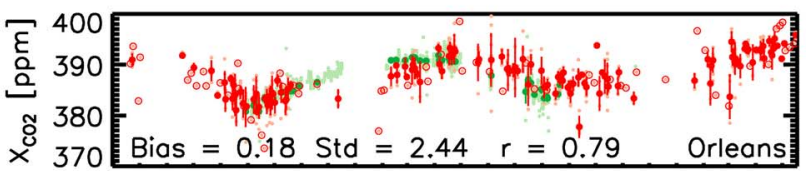

A M J JASOND JFMAM J JASOND JFMAM Month of Year (2009-2011)

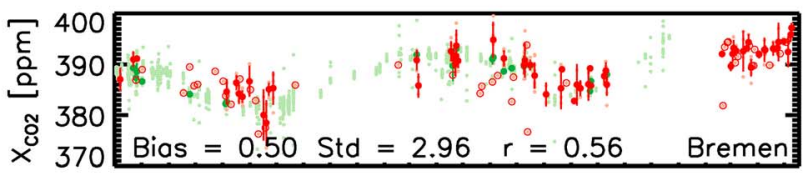

$A M J J A S O N D J F M A M J J A S O N D J F M A M$ Month of Year (2009-2011)

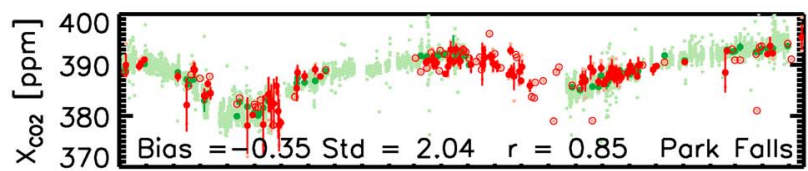

$A M J J A S O N D J F M A M J J A S O N D J F M A M$ Month of Year (2009-2011)

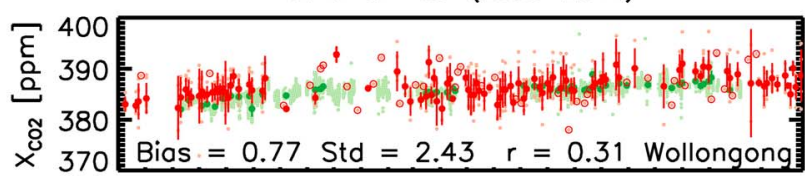

$A M J J A S O N D J F M A M J J A S O N D J F M A M$ Month of Year (2009-2011)

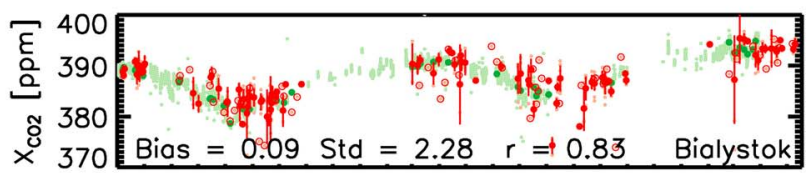

AM J JASOND JFMAM J JASOND JFMAM Month of Year (2009-2011)

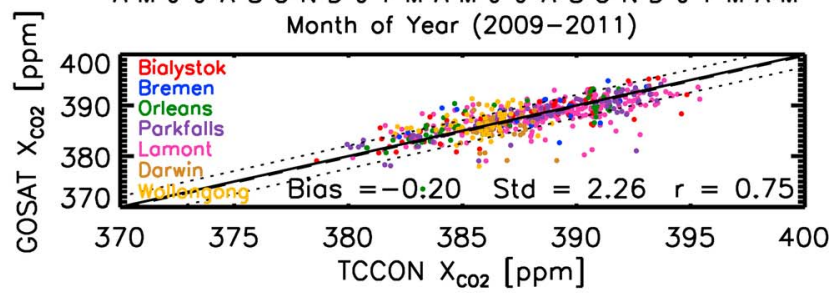

Figure 2. Comparison of retrieved $\mathrm{X}_{\mathrm{CO}_{2}}$ from GOSAT with retrieved $\mathrm{X}_{\mathrm{CO}_{2}}$ from seven TCCON site for coincident cloud-screened observations within 2 hours and $5^{\circ}$ between April 2009 and May 2011. All TCCON data shown in light green, coincident daily mean TCCON shown in dark green, all GOSAT data shown in light red and daily mean GOSAT shown in dark red (with daily mean points with only one value per day are represented by open circles). The average difference between the daily means is given as the bias (ranging from -0.87 to $0.77 \mathrm{ppm}$ ), the standard deviation of daily means by the Std (between 2.04 and $2.96 \mathrm{ppm})$ and the correlation coefficient of daily means by $\mathrm{r}$ ( -0.10 at Darwin to 0.85 at Park Falls). The lower right panel gives the correlation of daily mean coincident retrieved GOSAT $\mathrm{X}_{\mathrm{CO}_{2}}$ with daily mean TCCON X $\mathrm{CO}_{2}$ within \pm 2 hours for the seven sites. This gives an overall bias of $-0.20 \mathrm{ppm}$, scatter of $2.26 \mathrm{ppm}$ and correlation of 0.75 between GOSAT and TCCON X $\mathrm{CO}_{2}$.

(factor of $\sim 2$ on average) larger than that predicted from the a posterior error, which we find on average to be $1.14 \mathrm{ppm}$. The additional scatter observed is likely introduced by cloud perturbations, variations of aerosols, and other geophysical parameters. A similar value is reported by O'Dell et al. [2012] from simulations.

[30] There are some outliers between GOSAT and TCCON retrievals that have passed our screening and are likely due to scattering caused by undetected clouds or aerosols. Thus, we have also tested the effect of applying stricter postscreening, which when applied caused many of these outliers to be removed, reducing the mean bias to $-0.08 \mathrm{ppm}$ and the scatter to $1.92 \mathrm{ppm}$ (of daily means), but at the cost of the number of exposures (see Table 4 for details).

[31] This comparison has not taken into account the effect of the different averaging kernels $\mathbf{A}$ and a priori, which describe the sensitivity of a retrieval algorithm to the true state throughout the atmosphere [Rodgers, 2000; Rodgers and Connor, 2003]. The retrieved $\mathrm{X}_{\mathrm{CO}_{2}}$ for GOSAT and TCCON depends on the averaging kernel and the a priori used in the retrieval algorithm according to:

$$
\mathbf{X}_{\mathbf{C O} 2}=\mathbf{h}^{\mathbf{T}} \mathbf{x}_{\mathbf{a}}+\mathbf{h}^{\mathbf{T}} \mathbf{A}\left(\mathbf{x}-\mathbf{x}_{\mathbf{a}}\right)
$$

where $\mathbf{h}^{T}$ is the transpose of the pressure weighting function [O'Dell, 2010], $\mathbf{x}$ is the true VMR profile, and $\mathbf{x}_{a}$ is the a priori VMR profile. A consequence of equation (1) is that the true and the retrieved $\mathrm{X}_{\mathrm{CO}_{2}}$ will differ if $\mathbf{A}$ is different from the Unity matrix. This difference is referred to as the smoothing error and it will be different for the GOSAT and TCCON retrievals due to their different averaging kernels and a priori values.

[32] We have assessed this effect on the comparison of $\mathrm{X}_{\mathrm{CO}_{2}}$ retrievals from GOSAT and TCCON by calculating the $\mathrm{X}_{\mathrm{CO}_{2}}$ retrieved from GOSAT and TCCON using GEOSChem model (described in Section 4) calculations as the true $\mathrm{CO}_{2}$ profile. Since the GEOS-Chem model calculations will not necessarily represent the true atmospheric $\mathrm{CO}_{2}$ profiles these values for smoothing error differences will only represent a rough estimate.

[33] For each of the seven TCCON sites considered, GEOS-Chem was interpolated temporally to the observation time of TCCON and GOSAT using the GEOS-Chem grid cell that includes the TCCON site. The averaging kernels were applied to GEOS-Chem for the period of April 2009 to December 2010 where both model, TCCON and GOSAT data exist. Only TCCON data that was temporally closest to 
GOSAT data, which was coincident within \pm 2 hours and $5^{\circ}$ of each TCCON site was used.

[34] The mean smoothing errors of TCCON and GOSAT were calculated as $0.12 \mathrm{ppm}$ and $0.27 \mathrm{ppm}$ respectively. The mean smoothing error difference between the model $\mathrm{X}_{\mathrm{CO}_{2}}$ with GOSAT averaging kernels applied and the model $\mathrm{X}_{\mathrm{CO}_{2}}$ with TCCON averaging kernels applied was found to be $-0.14 \mathrm{ppm}$. The average of the mean smoothing error difference per station is $-0.22 \mathrm{ppm}$ with Lamont having the smallest mean smoothing error difference of $-0.05 \mathrm{ppm}$ and Orleans having the largest mean smoothing error difference of $-0.50 \mathrm{ppm}$. The standard deviation of the mean smoothing error difference per site is $0.18 \mathrm{ppm}$. The mean of the scatter of the smoothing error difference per station is $0.19 \mathrm{ppm}$, with a standard deviation of $0.09 \mathrm{ppm}$. We observe the smoothing error difference to have a small seasonal cycle dependence, with northern hemispheric sites varying from approximately $-1.5 \mathrm{ppm}$ to $0.5 \mathrm{ppm}$ and a lower amplitude for southern hemisphere stations where the seasonal cycle is reduced. Hence, for southern hemispheric sites the difference of the smoothing errors has a very small impact on the comparison of GOSAT with TCCON. However, for northern hemispheric sites there is a seasonal cycle dependence between GOSAT and TCCON $\mathrm{X}_{\mathrm{CO}_{2}}$ due to the smoothing error difference (see Figure 3). If we apply the point-by-point smoothing error difference to the coincident TCCON data, we find the mean bias of GOSAT compared to TCCON to increase by $0.14 \mathrm{ppm}$ but the standard deviation and correlation coefficient to remain the same (see Table 5 for further details). It cannot be expected that the estimates are necessarily representing the correct value for each individual sounding as this would require that the model reproduces the shape of the $\mathrm{CO}_{2}$ profile at each time step and location. Indeed, we find that including the smoothing error estimates from GEOS-Chem to the GOSAT-TCCON comparisons worsens the comparisons for some sites while it improves it for others.

\section{Comparison to the GEOS-Chem Chemistry Transport Model}

[35] We compare one year of GOSAT $\mathrm{X}_{\mathrm{CO}_{2}}$ retrievals with $\mathrm{CO}_{2}$ atmospheric concentrations from the GEOS-Chem global 3-D chemistry transport model (v8-02-01) [Feng et al., 2011]. The GEOS-Chem simulations use assimilated GEOS-5 meteorology from the Global Modeling and Assimilation Office based at NASA Goddard to drive the model. For the surface $\mathrm{CO}_{2}$ fluxes, GEOS-Chem assimilates annual fossil fuel emissions estimated from CDIAC, biofuel emissions obtained from Yevich and Logan [2003] climatology, monthly biomass burning emissions extracted from the third version of the Global Fire Emission Database (GFEDv3) that uses observations of the land surface by ground-based and satellite instruments, monthly ocean fluxes that are derived from sea-surface $\mathrm{pCO}_{2}$ observations [Takahashi et al., 2009], and biospheric fluxes that are computed using the CASA biosphere model [Randerson et al., 1997]. The CASA model is three hourly and is constrained by GEOSmeteorology output and Normalized Difference Vegetation Index (NDVI). The mixing depths and surface fields are updated every three hours and the GEOS-5 meteorology is updated every six hours. The $4 \mathrm{D}$ fields include 

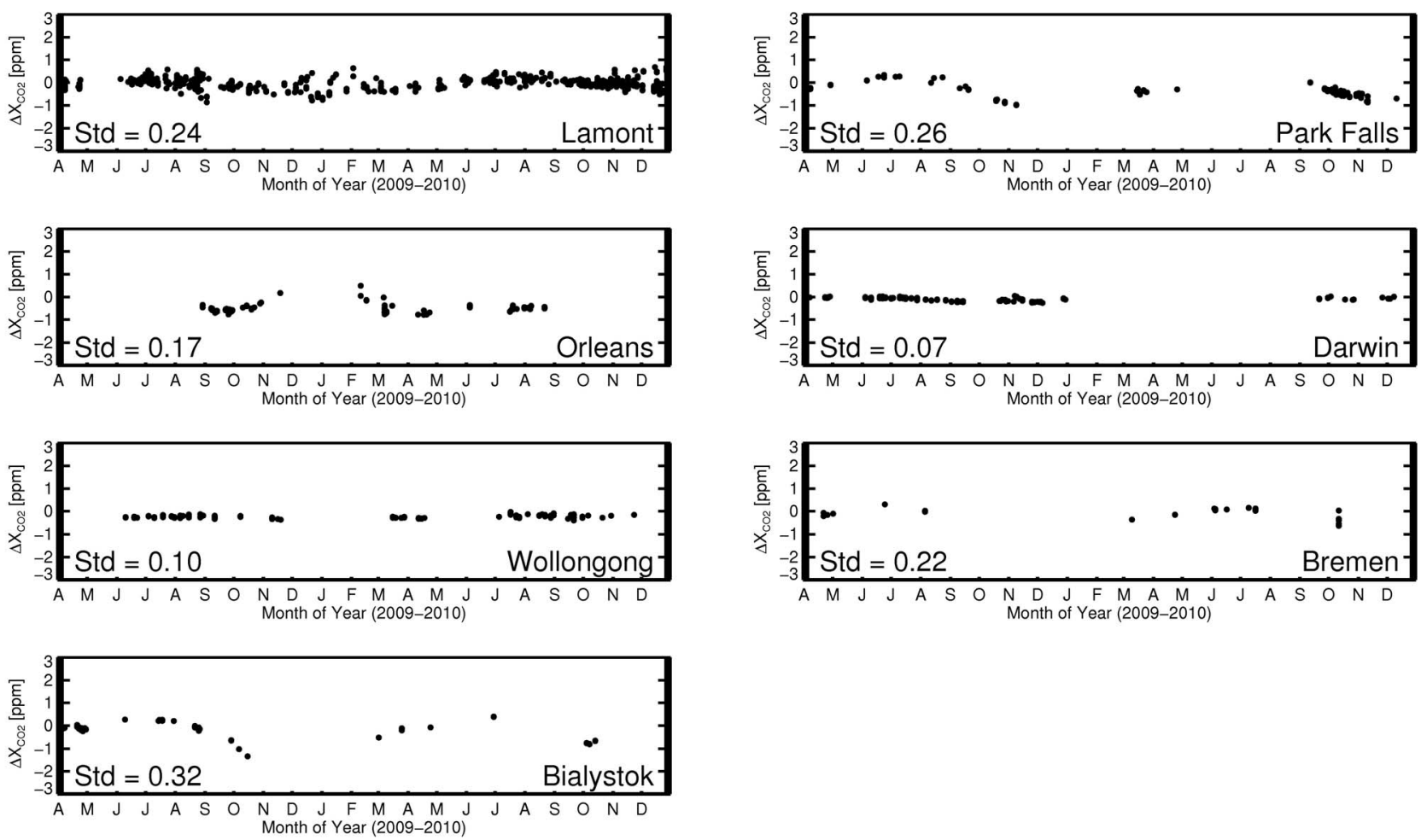

Figure 3. Calculated smoothing error differences for seven TCCON sites, for coincident cloud-screened observations within 2 hours and $5^{\circ}$ between April 2009 and December 2010. The standard deviation of the smoothing error difference values are given by the Std (between 0.07 and $0.32 \mathrm{ppm}$ ).

47 vertical levels and a horizontal grid resolution of $2^{\circ}$ latitude by $2.5^{\circ}$ longitude.

[36] The GEOS-Chem simulations are forced by posterior fluxes inferred from the GLOBALVIEW $\mathrm{CO}_{2}$ product, that includes 2009 to 2010 data [GLOBALVIEW-CO2, 2011]. The GLOBALVIEW data from 78 surface sites are assimilated to estimate monthly surface fluxes over 144 global regions by using an ensemble Kalman Filter (EnKF) [Feng et al., 2009, 2011]. Feng et al. [2011] reported that the GEOS-Chem model is within $1.5 \mathrm{ppm}$ of free and upper troposphere aircraft vertical profile measurements and $\mathrm{CO}_{2}$ retrieved from Atmospheric InfraRed Sounder (AIRS) observations. Additionally, GEOS-Chem is on average within 0.5 to $1.0 \mathrm{ppm}$ of observed partial $\mathrm{CO}_{2}$ columns from the HIAPER Pole-to-Pole

Table 5. Statistics for the UoL-FP v3G Comparison to TCCON With and Without TCCON Data Being Corrected by the Smoothing Error Difference (SED) Between GOSAT and TCCON ${ }^{\mathrm{a}}$

\begin{tabular}{|c|c|c|c|c|c|c|c|c|c|}
\hline $\begin{array}{l}\text { TCCON } \\
\text { Site }\end{array}$ & $\begin{array}{l}\text { Bias Without } \\
\text { SED (ppm) }\end{array}$ & $\begin{array}{c}\sigma \text { Without } \\
\text { SED (ppm) }\end{array}$ & $\begin{array}{c}\text { r Without } \\
\text { SED (Pearson) }\end{array}$ & $\begin{array}{l}\text { Bias With } \\
\text { SED (ppm) }\end{array}$ & $\begin{array}{c}\sigma \text { With } \\
\text { SED (ppm) }\end{array}$ & $\begin{array}{l}\mathrm{r} \text { With SED } \\
\text { (Pearson) }\end{array}$ & $\begin{array}{c}\text { Bias } \\
\text { Difference } \\
\text { (ppm) }\end{array}$ & $\begin{array}{c}\sigma \text { Difference } \\
(\mathrm{ppm})\end{array}$ & $\begin{array}{c}\text { r Difference } \\
\text { (Pearson) }\end{array}$ \\
\hline $\begin{array}{l}\text { Bialystok } \\
\left(53.230^{\circ} \mathrm{N}\right)\end{array}$ & -0.13 & 2.34 & 0.73 & -0.34 & 2.47 & 0.7 & -0.21 & 0.13 & -0.03 \\
\hline $\begin{array}{l}\text { Bremen } \\
\left(53.100^{\circ} \mathrm{N}\right)\end{array}$ & 0.43 & 2.73 & 0.64 & 0.39 & 2.77 & 0.64 & -0.04 & 0.04 & 0.00 \\
\hline $\begin{array}{l}\text { Orleans } \\
\left(47.970^{\circ} \mathrm{N}\right)\end{array}$ & -0.44 & 2.48 & 0.73 & -0.91 & 2.44 & 0.74 & -0.47 & -0.04 & 0.00 \\
\hline $\begin{array}{l}\text { Park Falls } \\
\left(45.945^{\circ} \mathrm{N}\right)\end{array}$ & -0.37 & 2.84 & 0.77 & -0.71 & 2.85 & 0.77 & -0.34 & 0.01 & 0.00 \\
\hline $\begin{array}{l}\text { Lamont } \\
\left(36.604^{\circ} \mathrm{N}\right)\end{array}$ & -0.08 & 2.23 & 0.66 & -0.09 & 2.23 & 0.66 & -0.01 & 0.00 & 0.00 \\
\hline $\begin{array}{l}\text { Darwin } \\
\left(12.424^{\circ} \mathrm{S}\right)\end{array}$ & -0.96 & 2.36 & 0.09 & -1.06 & 2.35 & 0.10 & -0.10 & -0.01 & 0.01 \\
\hline $\begin{array}{l}\text { Wollongong } \\
\left(34.406^{\circ} \mathrm{S}\right)\end{array}$ & 0.91 & 2.47 & 0.24 & 0.67 & 2.47 & 0.24 & -0.24 & 0.00 & 0.00 \\
\hline Total & -0.15 & 2.44 & 0.66 & -0.29 & 2.44 & 0.66 & -0.14 & 0.00 & 0.00 \\
\hline
\end{tabular}

${ }^{\text {a }}$ The bias, $\sigma$ and $\mathrm{r}$ were calculated using coincident daily mean data and other parameters calculated from individual coincident points, between April 2009 and December 2010. 

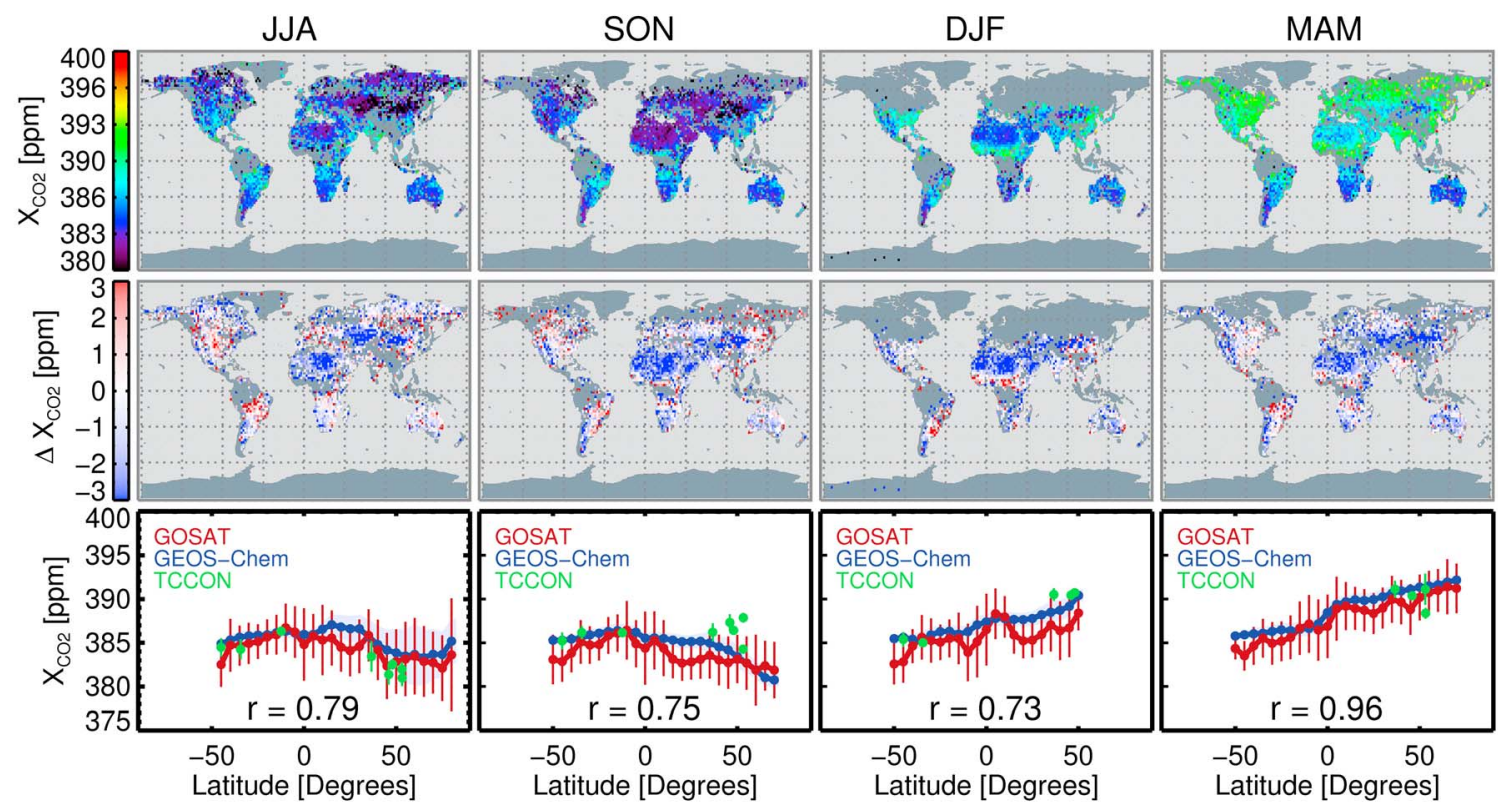

Figure 4. Comparison of $\mathrm{X}_{\mathrm{CO}_{2}}$ retrieved from GOSAT and $\mathrm{X}_{\mathrm{CO}_{2}}$ calculated from GEOS-Chem $\mathrm{CO}_{2}$ profiles convolved with the scene-specific GOSAT averaging kernel. Shown for each season is (top) $\mathrm{X}_{\mathrm{CO}_{2}}$ retrieved from GOSAT, (middle) the difference between GOSAT and GEOS-Chem, and (bottom) a zonal mean comparison of them. The global maps indicate the largest differences are observed over desert regions, such as the Sahara and central Asia. The zonal mean comparison shows a very good agreement between GOSAT and GEOS-Chem. It also includes the average TCCON X $\mathrm{CO}_{2}$ from each site which in general agrees, with observed differences mostly due to zonal averaging of GOSAT/GEOS-Chem data.

Observation (HIPPO) project (James Barlow, personal communication, 2012). The GEOS-Chem model vertical transport errors are estimated to be less than $\sim 2 \mathrm{ppm}$. This is supported by complementary model evaluation studies of $\mathrm{CH}_{4}, \mathrm{CH}_{3} \mathrm{CCl}_{3}$, and $\mathrm{SF}_{6}$ [e.g., Fraser et al., 2011; Patra et al., 2011]. We have compared TCCON X $\mathrm{CO}_{2}$ with that of GEOS-Chem (convolved with the TCCON averaging kernels) for each of the seven sites considered and find GEOS-Chem to have a mean bias of $-0.09 \mathrm{ppm}$, standard deviation of $1.23 \mathrm{ppm}$ and correlation coefficient of 0.93 , comparing better than GOSAT with TCCON (see Figure A1). Based on our current understanding of model performance we conclude that the model should well reproduce large scale features of the atmospheric $\mathrm{CO}_{2}$ distribution and that differences between GOSAT and GEOS-Chem are likely due to GOSAT retrieval biases. Although, model errors could also contribute to any observed differences.

[37] Figure 4 shows the comparison between $\mathrm{X}_{\mathrm{CO}_{2}}$ from GOSAT and GEOS-Chem for each season, where the GEOSChem $\mathrm{CO}_{2}$ profiles were interpolated to the locations and times of the GOSAT observations, and convolved with the averaging kernel (equation (1)) to obtain $\mathrm{X}_{\mathrm{CO}_{2}}$ as measured by GOSAT. Overall, the spatial and temporal distribution of $\mathrm{X}_{\mathrm{CO}_{2}}$ agrees well between GOSAT and GEOS-Chem. The mean difference observed between GOSAT and GEOSChem $\mathrm{X}_{\mathrm{CO}_{2}}$ varies from -1.43 to $-0.82 \mathrm{ppm}$ seasonally, with the standard deviation ranging from 2.41 to $2.71 \mathrm{ppm}$. We find high correlations of the seasonal latitudinal gradient with correlation coefficients ranging between 0.73 and 0.96 , but slightly poorer global point-by-point correlation coefficients with values between 0.37 and 0.64 . Between June 2009 and May 2010 we find the correlation between the GOSAT and GEOS-Chem annual mean latitudinal gradient is 0.76 and the annual spatial variability to have a global mean difference of $-1.22 \mathrm{ppm}$, standard deviation of $2.59 \mathrm{ppm}$ and correlation of 0.61 (not shown in figures).

[38] Over desert regions such as the Sahara, Saudi Arabia and Australia, we find differences between GOSAT and GEOS-Chem of up to $3 \mathrm{ppm}$. The medium gain mode is predominantly used over desert areas where surface reflectance causes the signal intensity to be high. Suto et al. [2011] found that TANSO-FTS instrument micro-vibrations produced a larger effect on medium gain observations and $\mathrm{X}_{\mathrm{CO}_{2}}$ retrievals of medium gain have been observed to be $\sim 1 \%$ higher than that of high gain [Crisp et al., 2012]. However, we find for desert regions observed with the high gain mode, such as central Asia, also give similar differences in $\mathrm{X}_{\mathrm{CO}_{2}}$ compared to GEOS-Chem. Since all these regions include high albedo in the 1.61 and $2.06 \mu \mathrm{m} \mathrm{CO}$ bands and high levels dust, the $\mathrm{X}_{\mathrm{CO}_{2}}$ difference is not solely due to gain issues (as suggested by Crisp et al. [2012]) but also potentially an aerosol or other instrumental related issue.

[39] The time series of $\mathrm{X}_{\mathrm{CO}_{2}}$ from GOSAT and GEOSChem for a number of different regions are shown in Figure 5. We find the seasonal cycle to match very well between GOSAT and GEOS-Chem for both northern and southern hemispheres, but we observe a difference of $1.5 \mathrm{ppm}$ in the northern hemisphere throughout the year and a smaller 


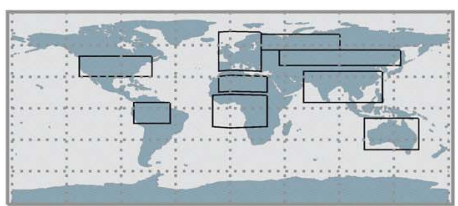

USA

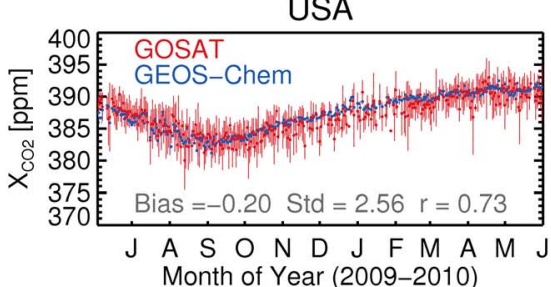

Amazon

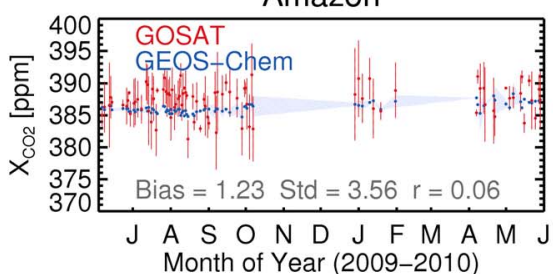

Australia

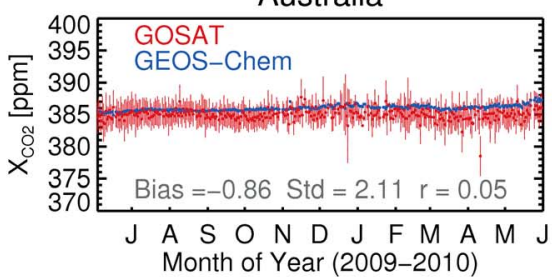

Month of Year (2009-2010)

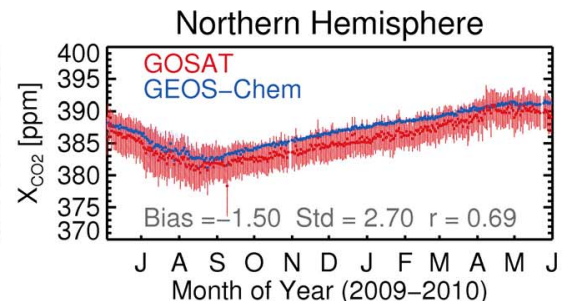

Europe

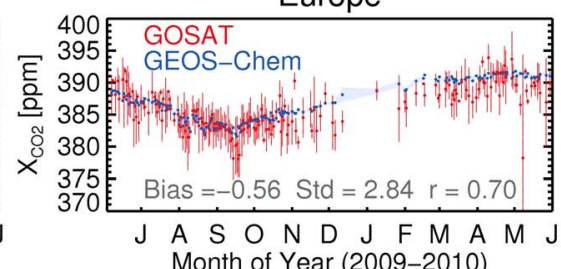

Month of Year (2009-2010)

Tropical Africa

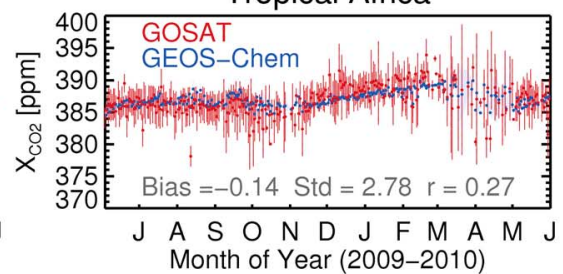

Sahara

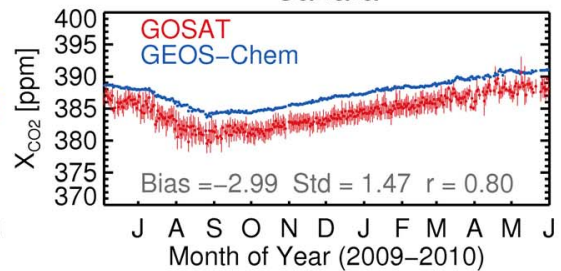

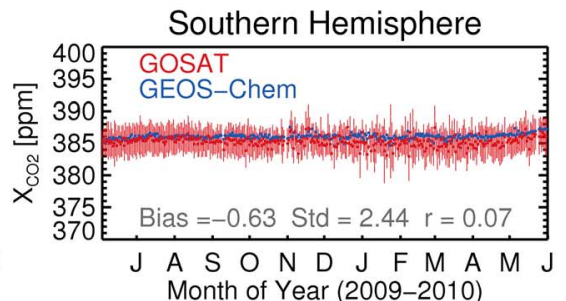

South ASIA

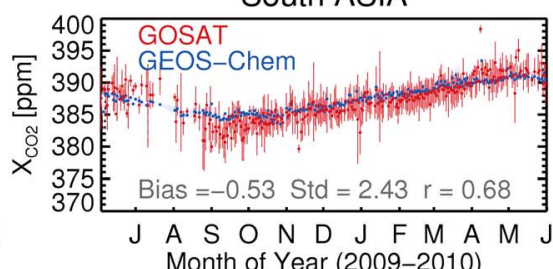

Month of Year (2009-2010)

NW Russia

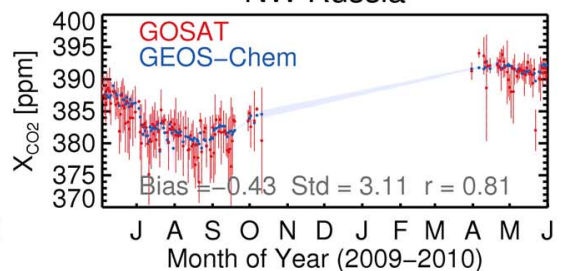

Central ASIA

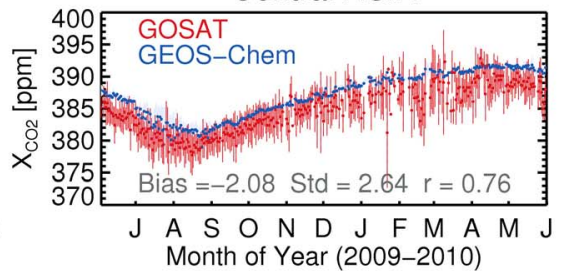

Figure 5. Comparison of $\mathrm{X}_{\mathrm{CO}_{2}}$ retrieved from GOSAT and $\mathrm{X}_{\mathrm{CO}_{2}}$ calculated from GEOS-Chem $\mathrm{CO}_{2}$ profiles convolved with the scene-specific GOSAT averaging kernel, for a number of different regions between June 2009 and May 2010. The locations of these regions are indicated on the map by the black boxes (top left). The top center and top right panels give the time series of GOSAT and GEOS-Chem data for the northern and southern hemispheres, showing the seasonal cycle to be well matched but with GOSAT data offset lower by $-1.50 \mathrm{ppm}$ in the northern hemisphere and $-0.63 \mathrm{ppm}$ in the southern hemisphere. The second row of plots show a very good agreement between GOSAT and GEOS-Chem both in value and seasonality for regions containing urban environments. Below these, the time series of forested regions are shown, with GOSAT reproducing the GEOS-Chem data very well but with a larger scatter and fewer data points. The bottom panels show the time series for 3 different desert regions, with GOSAT matching the seasonal cycle of GEOS-Chem very well but offset lower in value from -0.86 to $-2.99 \mathrm{ppm}$.

difference of $0.63 \mathrm{ppm}$ in the southern hemisphere. GOSAT and GEOS-Chem $\mathrm{X}_{\mathrm{CO}_{2}}$ show a high consistency for both Europe and the USA, with a $\mathrm{X}_{\mathrm{CO}_{2}}$ difference of $0.20 \mathrm{ppm}$ and $0.56 \mathrm{ppm}$ and correlation coefficients of 0.73 and 0.70 , respectively. On average, GOSAT and GEOS-Chem agree for South Asia with a mean difference of $0.53 \mathrm{ppm}$ and correlation coefficient of 0.68 , but we view differences in the seasonal cycle with GEOS-Chem over-estimating the $\mathrm{X}_{\mathrm{CO}_{2}}$ in autumn 2009 and under-estimating during spring 2010.

[40] Few GOSAT soundings are observed over the Amazon due to tropical clouds, and those measurements that are retrieved have a large standard deviation $(3.56 \mathrm{ppm})$ that is potentially due to partial cloud contamination. Similarly, we see a larger scatter intropical Africa during autumn and spring for GOSAT, whereas winter and summer have a reduced scatter and have similar values as GEOS-Chem. A very high agreement is observed for NW Russia with a correlation coefficient of 0.81 and a mean $\mathrm{X}_{\mathrm{CO}_{2}}$ difference of $0.43 \mathrm{ppm}$.

[41] In central Asia where a desert region is observed with the high gain mode, we observe the seasonal cycle of GOSAT and GEOS-Chem to agree well $(r=0.76)$, but consistently with a $\sim 2 \mathrm{ppm}$ difference in value. We also find a $\sim 3 \mathrm{ppm}$ mean difference over the Sahara between GOSAT and GEOS-Chem $\mathrm{X}_{\mathrm{CO}_{2}}$ where a desert region is observed with the medium gain mode, but the seasonal cycle agrees well with a correlation coefficient of 0.80 . Australia, which comprises partially of desert and is observed partially with medium 


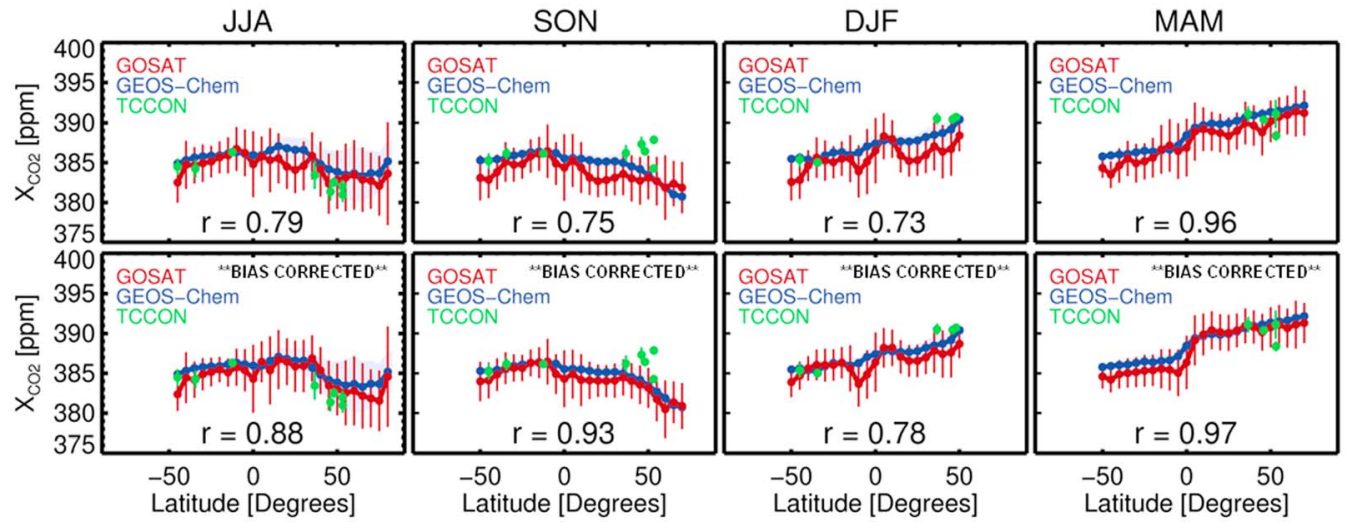

Figure 6. (top) Zonal mean comparisons for each season of $\mathrm{X}_{\mathrm{CO}_{2}}$ retrieved from GOSAT and $\mathrm{X}_{\mathrm{CO}_{2}}$ calculated from GEOS-Chem $\mathrm{CO}_{2}$ profiles convolved with the scene-specific GOSAT averaging kernel. (bottom) Revised comparisons where the GOSAT $\mathrm{X}_{\mathrm{CO}_{2}}$ was bias corrected. The latitudinal gradients of the bias corrected GOSAT $\mathrm{X}_{\mathrm{CO}_{2}}$ match very well to GEOS-Chem with correlations between 0.78 and 0.97 . The bias correction leads to increases of the correlation between 0.01 and 0.18 , and shows a large improvement over the latitudes that contain the Sahara.

and high gain modes, also shows a difference in $\mathrm{X}_{\mathrm{CO}_{2}}$ between GOSAT and GEOS-Chem with a value of $0.86 \mathrm{ppm}$.

\section{Bias Correction Scheme}

[42] A bias correction method was developed to help identify and reduce the observed biases of retrieved $\mathrm{X}_{\mathrm{CO}_{2}}$ from GOSAT, especially over desert areas. Similar to Wunch et al. [2011b], our bias correction method is based on a multivariate linear regression of the difference between pseudo observations and retrieved $\mathrm{X}_{\mathrm{CO}_{2}}$ from GOSAT between July 2009 to June 2010 over the region south $25^{\circ} \mathrm{S}$ where the variability of $\mathrm{CO}_{2}$ is low. The pseudo-observations were generated using GEOS-Chem calculations to provide information on vertical profile and spatial variations while the temporal variations and absolute values were scaled to match Wollongong/Australia $\left(34.406^{\circ} \mathrm{S}\right)$ and Lauder/New Zealand $\left(45.038^{\circ} \mathrm{S}\right) \mathrm{TCCON}$ measurements. Initially we used all retrieval parameters and observation related parameters. Similar to Wunch et al. [2011b], we then identified the four parameters with the highest correlation to obtain the following equation:

$$
\begin{aligned}
\mathrm{X}_{\mathrm{CO}_{2}}^{\text {bias-corrected }}[\mathrm{ppm}]= & \mathrm{X}_{\mathrm{CO}_{2}}^{\text {retrieved }}[\mathrm{ppm}]+4.19 \\
& -0.564 * \mathrm{CO}_{2} \text { Signal_Ratio } \\
& -0.193 *(\Delta \mathrm{P}[\mathrm{hPa}]) \\
& +56.8 * \text { Ice_Optical_Depth } \\
& +0.256 * 10^{-5} * \mathrm{O}_{2} \text { _Albedo_Slope }
\end{aligned}
$$

These parameters have been identified by the regression which does not provide a means of identifying the physical link. We observe a correlation $(\mathrm{r}=0.37)$ of the $\mathrm{X}_{\mathrm{CO}_{2}}$ difference with the ratio of the mean signal of the $1.61 \mu \mathrm{m} \mathrm{CO}_{2}$ band to the $2.06 \mu \mathrm{m} \mathrm{CO} \mathrm{CO}_{2}$ band $\left(\mathrm{CO}_{2}\right.$ SSignal_Ratio), which may be a consequence of the spectroscopic differences of the different
$\mathrm{CO}_{2}$ bands, but might also relate to aerosols or albedo. Spectroscopic errors may also result in systematic effects in the retrieved surface pressure as shown by Wunch et al. [2011b] and we find the $\mathrm{X}_{\mathrm{CO}_{2}}$ difference to correlate $(\mathrm{r}=0.30)$ with delta surface pressure $(\triangle \mathrm{P})$, even though we already normalize the $\mathrm{X}_{\mathrm{CO}_{2}}$ with the surface pressure ratio. An anti-correlation $(\mathrm{r}=-0.22)$ of the $\mathrm{X}_{\mathrm{CO}_{2}}$ difference with retrieved cirrus optical depth (Ice_Optical_Depth) is observed which indicates the path length was altered. Based on the geographical location of the bias correction for this parameter we can tell the ice optical depth refers to cirrus clouds. We also find an anti-correlation $(\mathrm{r}=-0.29)$ of the $\mathrm{X}_{\mathrm{CO}_{2}}$ difference with the slope of the band 1 albedo $\left(\mathrm{O}_{2}\right.$ Albedo_Slope $)$ which may be due to errors in the $\mathrm{O}_{2}$ A band spectroscopy, zero-level offsets, or variations in signal intensity over vegetation regions that could be caused by not accounting for the known fluorescence [Frankenberg et al., 2011].

[43] Whilst Wunch et al. [2011b] found biases partially due to air mass and the $\mathrm{O}_{2} \mathrm{~A}$ band signal, we do not find any correlation between the air mass and the $\mathrm{X}_{\mathrm{CO}_{2}}$ difference $(\mathrm{r}=0.01)$ nor the $\mathrm{O}_{2} \mathrm{~A}$ band signal $(\mathrm{r}=0.01)$. Additionally, we already retrieve a zero level offset in the $\mathrm{O}_{2} \mathrm{~A}$ band to mitigate the effects of the GOSAT Band 1 non-linearity and partially fluorescence [Butz et al., 2011; Frankenberg et al., 2011, 2012; Suto et al., 2011].

[44] We applied this bias correction to one year (June 2009 to May 2010) of $\mathrm{X}_{\mathrm{CO}_{2}}$ retrieved from GOSAT globally and compared it to $\mathrm{X}_{\mathrm{CO}_{2}}$ calculated from the GEOS-Chem model with GOSAT averaging kernels applied. We find the annual mean global difference to be reduced from $-1.22 \mathrm{ppm}$ to $-0.68 \mathrm{ppm}$ and the correlation to increase from 0.61 to 0.74 .

[45] Figure 6 shows a comparison between GOSAT and GEOS-Chem $\mathrm{X}_{\mathrm{CO}_{2}}$ latitudinal gradients for each season, comparing with and without the bias correction. The seasonal latitudinal gradients show improvements with increases of the correlation between 0.01 and 0.18 depending on the season, for DJF the improvement in correlation coefficient is marginal. 


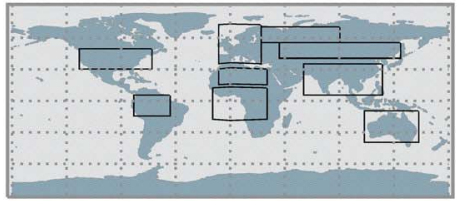

USA

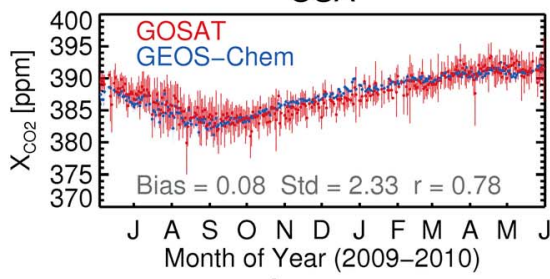

Amazon

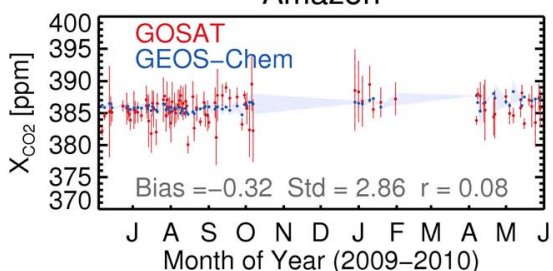

Australia

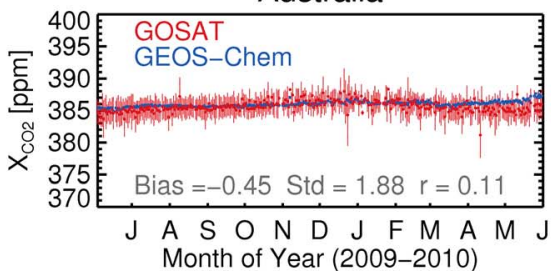

Month of Year (2009-2010)

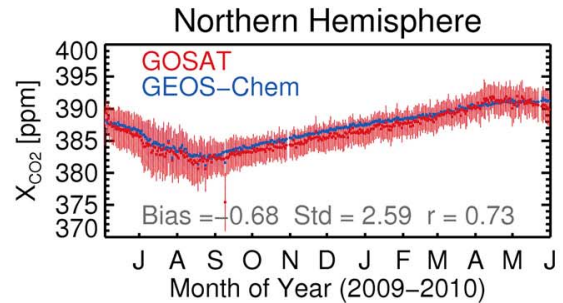

Europe

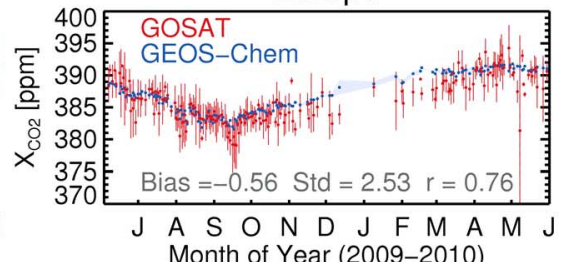

Month of Year (2009-2010)

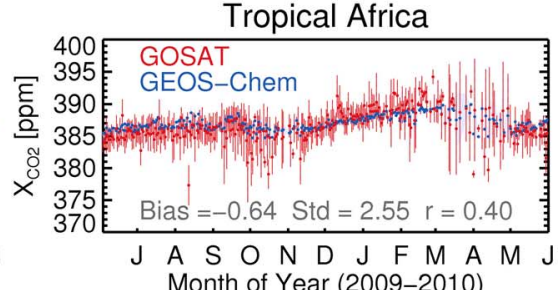

Month of Year (2009-2010)

Sahara

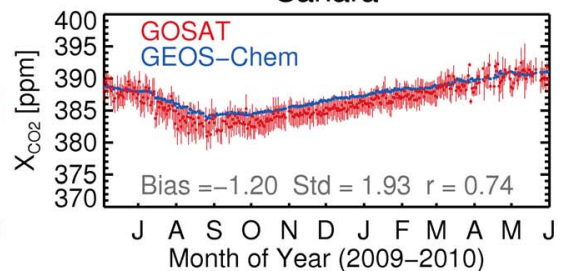

Southern Hemisphere

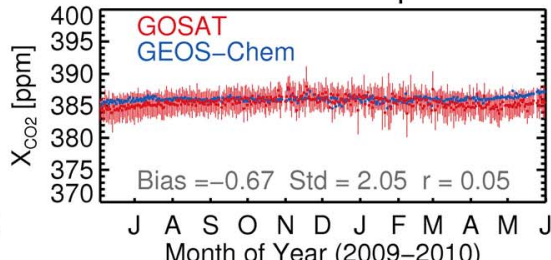

South ASIA

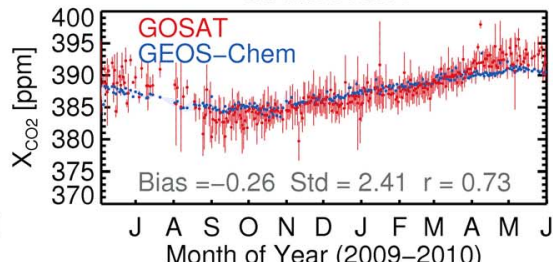

NW Russia

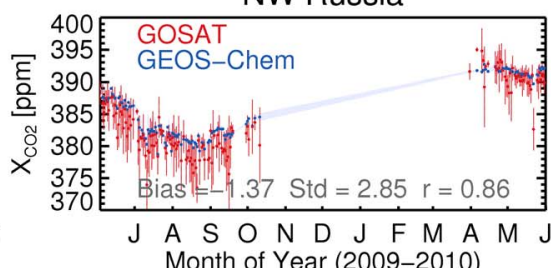

Central ASIA

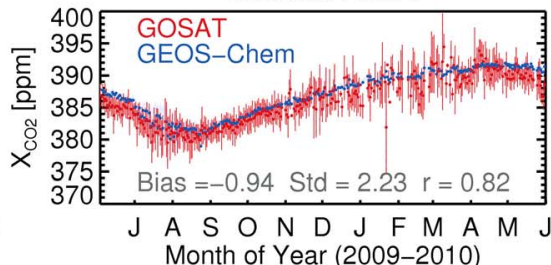

Figure 7. Comparison of bias corrected $\mathrm{X}_{\mathrm{CO}_{2}}$ retrieved from GOSAT and $\mathrm{X}_{\mathrm{CO}_{2}}$ calculated from GEOSChem $\mathrm{CO}_{2}$ profiles convolved with the scene-specific GOSAT averaging kernel, for a number of different regions between June 2009 and May 2010. The locations of these regions are indicated on the map by the black boxes (top left). GOSAT agrees very well with GEOS-Chem for both hemispheres and all regions. GOSAT shows a good reproduction of the seasonal cycle of GEOS-Chem data, with the exception of south Asia where GOSAT is higher in the summer period. Minor offsets exist over the desert regions, such as Australia, the Sahara, and central Asia, which is a large improvement compared to the non-bias corrected $\mathrm{X}_{\mathrm{CO}_{2}}$ shown in Figure 5. Additionally, the scatter of all regions is less than that of the non-bias corrected $\mathrm{X}_{\mathrm{CO}_{2}}$. Furthermore, the bias correction has brought the $\mathrm{X}_{\mathrm{CO}_{2}}$ over the Amazon to be of the same magnitude as GEOS-Chem.

The majority of the improvement occurs in the northern hemisphere, especially over the Sahara region.

[46] The time series of bias corrected $\mathrm{X}_{\mathrm{CO}_{2}}$ retrieved from GOSAT compared to GEOS-Chem data for different regions is shown in Figure 7. We find that for most regions the bias, standard deviation and correlation coefficient have improved. In particular, the bias correction has considerably reduced the larger differences previously seen over desert regions; the difference over the Sahara has reduced from $-2.99 \mathrm{ppm}$ to $-1.20 \mathrm{ppm}$, the difference over Australia has reduced to about half, and the difference over central Asia improved from $-2.08 \mathrm{ppm}$ to $-0.94 \mathrm{ppm}$. However, for the Sahara region, the standard deviation and correlation coefficient becomes worse. We also find that for some regions (Tropical
Africa and NW Russia) the bias increases when applying the bias correction.

\section{Conclusions}

[47] We introduce $\mathrm{X}_{\mathrm{CO}_{2}}$ retrievals from GOSAT using the UoL-FP v $3 \mathrm{G}$ algorithm and show from comparison to groundbased TCCON data that the retrievals have a random error of $\sim 2.5 \mathrm{ppm}$, twice the a posteriori error estimate. With stricter screening this precision reduces to $\sim 1.9 \mathrm{ppm}$, which should be sufficient to allow improved surface flux estimates [e.g., Chevallier, 2007; Chevallier et al., 2009; Miller et al., 2007]. The mean bias inferred from TCCON comparisons is $0.2 \mathrm{ppm}$ with a station-to-station variation of $0.56 \mathrm{ppm}$ (standard deviation). Thus, over TCCON sites the $\mathrm{X}_{\mathrm{CO}_{2}}$ retrieval is very 


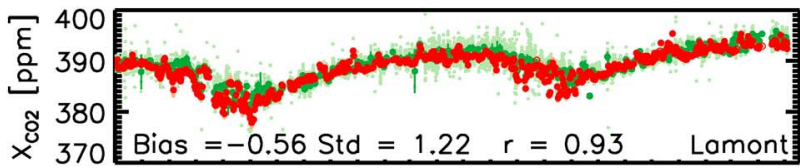

$A M J J A S O N D J F M A M J J A S O N D J F M A M$ Month of Year (2009-2011)

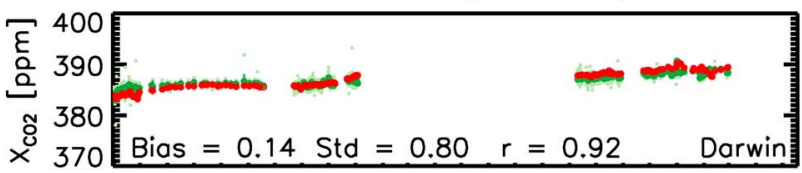

$A M J J A S O N D J F M A M J J A S O N D J F M A M$ Month of Year (2009-2011)

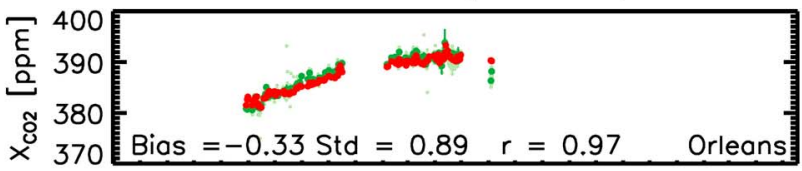

$A M J J A S O N D J F M A M J J A S O N D J F M A M$ Month of Year (2009-2011)

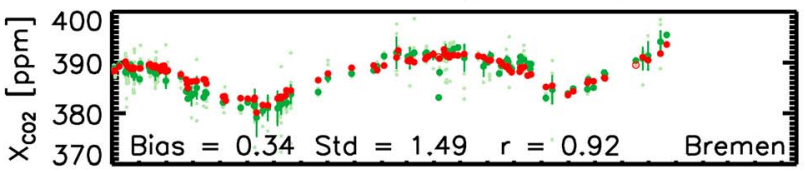

$A M J J A S O N D J F M A M J J A S O N D J F M A M$ Month of Year (2009-2011)

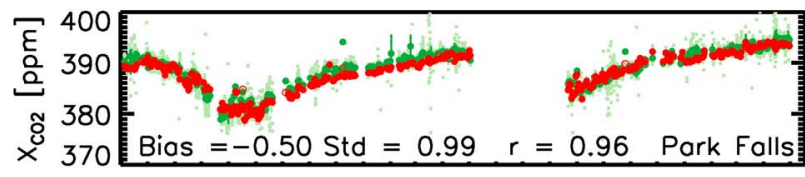

$A M J J A S O N D J F M A M J J A S O N D J F M A M$ Month of Year (2009-2011)

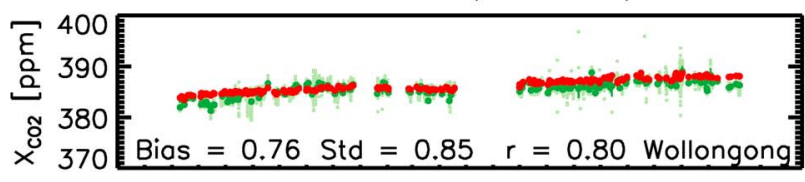

$A M J J A S O N D J F M A M J J A S O N D J F M A M$ Month of Year (2009-2011)

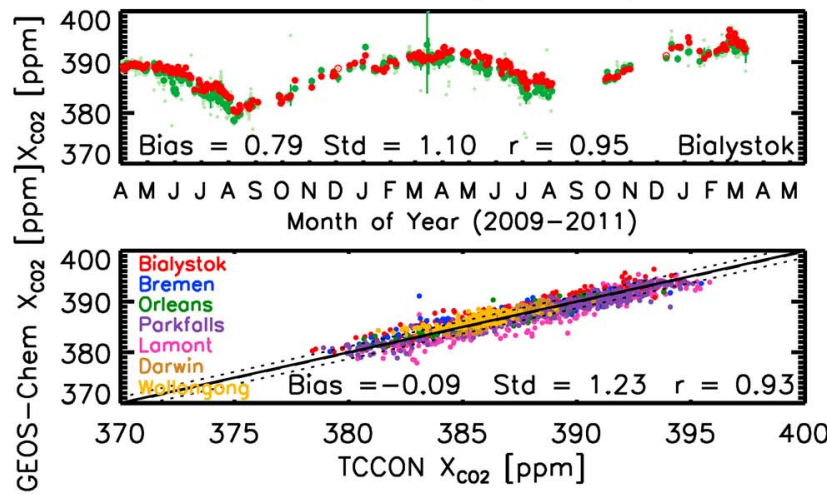

Figure A1. Comparison of $\mathrm{X}_{\mathrm{CO}_{2}}$ calculated from GEOS-Chem (with TCCON averaging kernels applied) with retrieved $\mathrm{X}_{\mathrm{CO}_{2}}$ from seven TCCON site for cloud-screened observations within $5^{\circ}$ between April 2009 and May 2011. All TCCON data shown in light green, coincident daily mean TCCON shown in dark green, all GEOS-Chem data shown in light red and daily mean GEOS-Chem shown in dark red (with daily mean points with only one value per day are represented by open circles). The average difference between the daily means is given as the bias (ranging from -0.56 to $0.79 \mathrm{ppm}$ ), the standard deviation of daily means by the Std (between 0.80 and $1.49 \mathrm{ppm}$ ) and the correlation coefficient of daily means by $\mathrm{r}$ (0.80 at Darwin to 0.97 at Orleans). The lower right panel gives the correlation of daily mean retrieved GEOS-Chem $\mathrm{X}_{\mathrm{CO}_{2}}$ with daily mean TCCON $\mathrm{X}_{\mathrm{CO}_{2}}$ for the seven sites. This gives an overall bias of $-0.09 \mathrm{ppm}$, scatter of $1.23 \mathrm{ppm}$ and correlation of 0.93 between GEOS-Chem and TCCON X $\mathrm{CO}_{2}$.

accurate with biases approaching only a few tenth ppm, which is close to typical retrieval requirements of systematic bias for $\mathrm{X}_{\mathrm{CO}_{2}}$ [e.g., Chevallier, 2007; Chevallier et al., 2009; Miller et al., 2007]. The latest results from other algorithms [Oshchepkov et al., 2009; Yokota et al., 2009; Butz et al., 2011; Morino et al., 2011; Wunch et al., 2011b; Yoshida et al., 2011; Crisp et al., 2012; Oshchepkov et al., 2012] find similar results with a variation in the number of soundings potentially due to the screening criteria applied. However, over desert regions, which are not observed by TCCON, we find that the retrieved $\mathrm{X}_{\mathrm{CO}_{2}}$ from GOSAT shows significant (up to $\sim 3 \mathrm{ppm}$ ) differences when compared to GEOSChem model calculations which we believe are biases in the GOSAT retrieval. Similar findings have been reported in Crisp et al. [2012] who suggested that these biases are related to instrument gain. We find that biases are observed for desert regions observed with both settings of the gain and we speculate that these biases could be introduced by desert dust or related to the high surface albedo in the $\mathrm{CO}_{2}$ bands. This study highlights the need for further algorithm improvements, especially over the deserts, but improvements in instrument calibration or spectroscopy might also lead to reduced biases for these regions. Until sufficient algorithmic improvements have been achieved, we suggest to either omit $\mathrm{X}_{\mathrm{CO}_{2}}$ retrievals over deserts or apply the described bias correction method which significantly reduces the biases in our $\mathrm{X}_{\mathrm{CO}_{2}}$ retrieved over deserts. However, except for the desert regions, the $\mathrm{X}_{\mathrm{CO}_{2}}$ retrievals approach the point where they should be useful for the inversion of $\mathrm{CO}_{2}$ surface fluxes with data assimilation methods [e.g., Baker et al., 2010; Chevallier et al., 2009; Feng et al., 2009].

\section{Appendix A: Comparison of GEOS-Chem With TCCON}

[48] Figure A1 shows a comparison of TCCON X $\mathrm{CO}_{2}$ with that of GEOS-Chem (convolved with the TCCON averaging kernels) for each of the seven sites considered in Section 3. We find GEOS-Chem to have a mean bias of $-0.09 \mathrm{ppm}$, standard deviation of $1.23 \mathrm{ppm}$ and correlation coefficient of 0.93 . Between stations, the bias has a range of -0.56 to 

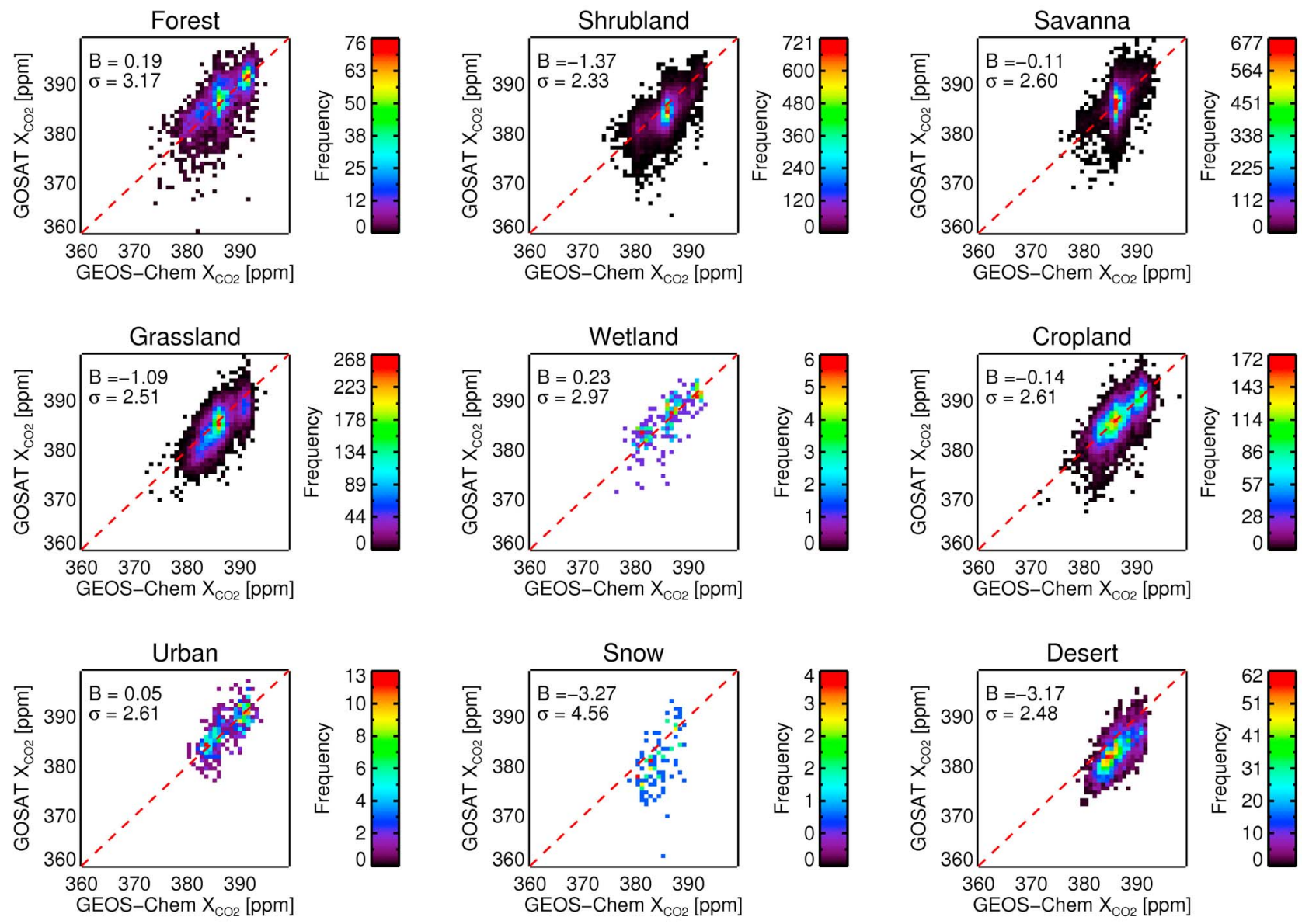

Figure B1. Comparison of $\mathrm{X}_{\mathrm{CO}_{2}}$ retrieved from high gain GOSAT data with GEOS-Chem $\mathrm{X}_{\mathrm{CO}_{2}}$ calculations for different MODIS land cover types. The red dashed line shows the one-to-one line, B represents the mean $\mathrm{X}_{\mathrm{CO}_{2}}$ difference, and $\sigma$ gives the standard deviation of $\mathrm{X}_{\mathrm{CO}_{2}}$. GOSAT and GEOS-Chem correlate well with $\mathrm{X}_{\mathrm{CO}_{2}}$ differences less than $0.23 \mathrm{ppm}$ for surfaces that consist of forest, cropland, savanna, wetland, or urban environments. However, larger $\mathrm{X}_{\mathrm{CO}_{2}}$ differences (up to $\sim 3.2 \mathrm{ppm}$ ) are found for surfaces that consist of desert, shrubland, grassland or snow.

$0.79 \mathrm{ppm}$, standard deviation between 0.80 and $1.49 \mathrm{ppm}$, and correlation coefficients ranging between 0.80 and 0.97 .

\section{Appendix B: Comparison of GOSAT With Land Surface Type}

[49] We have compared the $\mathrm{X}_{\mathrm{CO}_{2}}$ difference between GOSAT and GEOS-Chem against the land surface type for each observation. The surface type was determined by using the most common land cover type within a coincidence of $\pm 0.1^{\circ}$ of the Moderate Resolution Imaging Spectroradiometer (MODIS) Level 3 yearly $0.05^{\circ}$ land cover type (MCD12C1) for 2007 (assuming the land cover has not significantly altered between 2007 and 2010). Figures B1 and B2 show this comparison for each of the GOSAT gain modes separately.

[50] For retrievals of GOSAT high gain data, GOSAT and GEOS-Chem correlate well with $\mathrm{X}_{\mathrm{CO}_{2}}$ differences less than $0.23 \mathrm{ppm}$ for surfaces that consist of forest, cropland, savanna, wetland, or urban environments. However, larger
$\mathrm{X}_{\mathrm{CO}_{2}}$ differences (up to $\sim 3.2 \mathrm{ppm}$ ) are found for surfaces that consist of desert, shrubland, grassland or snow.

[51] Where medium gain data has been retrieved, $\mathrm{X}_{\mathrm{CO}_{2}}$ differences are found to be similar to that of high gain data. The retrieved $\mathrm{X}_{\mathrm{CO}_{2}}$ from GOSAT is found on average to be $\sim 1.5 \mathrm{ppm}$ lower than GEOS-Chem over both shrubland and grassland surfaces. The largest $\mathrm{X}_{\mathrm{CO}_{2}}$ difference of $2.75 \mathrm{ppm}$ is observed over desert surfaces. The lowest difference $(0.35 \mathrm{ppm})$ is found over savanna surfaces. No observations over other surface types exist due to the specific observation locations where medium gain was used. We find the $\mathrm{X}_{\mathrm{CO}_{2}}$ differences to be larger with certain land surface types, specifically deserts, irrespective of the gain setting used. This may, however, be different for alternative retrieval algorithms that do not correct for the systematic overestimates of surface pressure by normalizing the retrieved $\mathrm{X}_{\mathrm{CO}_{2}}$ with the ratio of retrieved surface pressure and ECMWF surface pressure. 

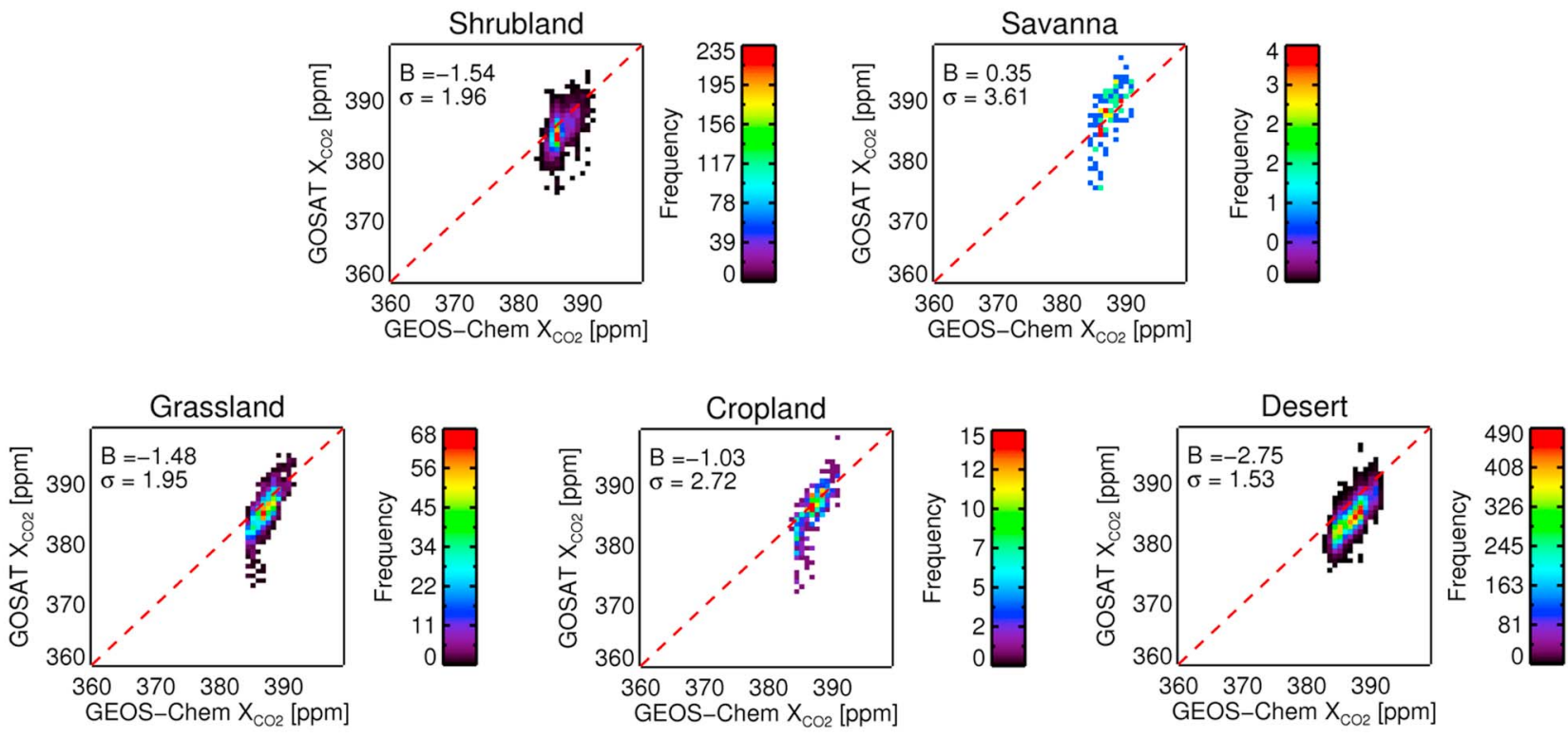

Figure B2. Comparison of $\mathrm{X}_{\mathrm{CO}_{2}}$ retrieved from medium gain GOSAT data with GEOS-Chem $\mathrm{X}_{\mathrm{CO}_{2}}$ calculations for different MODIS land cover types. The red dashed line shows the one-to-one line, B represents the mean $\mathrm{X}_{\mathrm{CO}_{2}}$ difference, and $\sigma$ gives the standard deviation of $\mathrm{X}_{\mathrm{CO}_{2}}$. The retrieved $\mathrm{X}_{\mathrm{CO}_{2}}$ from GOSAT is found on average to be $\sim 1.5 \mathrm{ppm}$ lower than GEOS-Chem over both shrubland and grassland surfaces. The largest $\mathrm{X}_{\mathrm{CO}_{2}}$ difference of $2.75 \mathrm{ppm}$ is observed over desert surfaces. The lowest difference $(0.35 \mathrm{ppm})$ is found over savanna surfaces. 
[52] Acknowledgments. We thank JAXA, NIES, and MOE for the GOSAT data and their continuous support as part of the Joint Research Agreement. A.C. is supported by the NERC, R.P., and L.F. are supported by the NCEO and H.B. is supported by a RCUK fellowship. We also thank the OCO team at JPL for providing the retrieval algorithm. We thank the BADC for providing ECMWF Operational Analyses data. U.S. funding for TCCON comes from NASA's Terrestrial Ecology Program, grant NNX11AG01G, the Orbiting Carbon Observatory Program, the Atmospheric $\mathrm{CO}_{2}$ Observations from Space (ACOS) Program and the DOE/ ARM Program of Research Science and Technology contracts C01X0204 and CO1X0406. Lauder TCCON data was obtained from the TCCON Data Archive, operated by the California Institute of Technology from the Web site at http://tccon.ipac.caltech.edu/. We acknowledge financial support of the Bialystok and Orleans TCCON sites from the Senate of Bremen and EU projects IMECC and GEOmon as well as maintenance and logistical work provided by AeroMeteo Service (Bialystok) and the RAMCES team at LSCE (Gif-sur-Yvette, France).

\section{References}

Baker, D. F., H. Boesch, S. C. Doney, D. O'Brien, and D. S. Schimel (2010), Carbon source/sink information provided by column $\mathrm{CO}_{2}$ measurements from the Orbiting Carbon Observatory, Atmos. Chem. Phys., 10, 4145-4165, doi:10.5194/acp-10-4145-2010.

Barkley, M. P., U. Frieß, and P. S. Monks (2006), Measuring atmospheric $\mathrm{CO}_{2}$ from space using full spectral initiation (FSI) WFM-DOAS, Atmos. Chem. Phys., 6, 3517-3534, doi:10.5194/acp-6-3517-2006.

Baum, B. A., P. Yang, A. J. Heymsfield, S. Platnick, M. D. King, Y.-X. Hu, and S. T. Bedka (2005), Bulk scattering properties for the remote sensing of ice clouds. Part 2: Narrowband models, J. Appl. Meteorol., 44, 18961911, doi:10.1175/JAM2309.1.

Boesch, H., et al. (2006), Space-based near-infrared $\mathrm{CO}_{2}$ measurements: Testing the Orbiting Carbon Observatory retrieval algorithm and validation concept using SCIAMACHY observations over Park Falls, Wisconsin, J. Geophys. Res., 111, D23302, doi:10.1029/2006JD007080.

Boesch, H., D. Baker, B. Connor, D. Crisp, and C. Miller (2011), Global characterization of $\mathrm{CO}_{2}$ column retrievals from shortwave-infrared satellite observations of the Orbiting Carbon Observatory-2 mission, Remote Sens., 3(2), 270-304, doi:10.3390/rs3020270.

Buchwitz, M., R. de Beek, S. Noel, J. P. Burrows, H. Bovensmann, H. Bremer, P. Bergamaschi, S. Korner, and M. Heimann (2005), Carbon monoxide, methane and carbon dioxide columns retrieved from SCIAMACHY by WFM-DOAS: Year 2003 initial data set, Atmos. Chem. Phys., 5, 3313-3329, doi:10.5194/acp-5-3313-2005.

Butz, A., et al. (2011), Toward accurate $\mathrm{CO}_{2}$ and $\mathrm{CH}_{4}$ observations from GOSAT, Geophys. Res. Lett., 38, L14812, doi:10.1029/2011GL047888.

Chevallier, F. (2007), Impact of correlated observation errors on inverted $\mathrm{CO}_{2}$ surface fluxes from OCO measurements, Geophys. Res. Lett., 34 L24804, doi:10.1029/2007GL030463.

Chevallier, F., S. Maksyutov, P. Bousquet, F.-M. Bréon, R. Saito, Y. Yoshida, and T. Yokota (2009), On the accuracy of the $\mathrm{CO}_{2}$ surface fluxes to be estimated from the GOSAT observations, Geophys. Res. Lett., 36, L19807, doi:10.1029/2009GL040108.

Christi, M. J., and G. L. Stephens (2004), Retrieving profiles of atmospheric $\mathrm{CO}_{2}$ in clear sky and in the presence of thin cloud using spectroscopy from the near and thermal infrared: A preliminary case study, J. Geophys. Res., 109, D04316, doi:10.1029/2003JD004058.

Connor, B. J., H. Boesch, G. Toon, B. Sen, C. Miller, and D. Crisp (2008), Orbiting Carbon Observatory: Inverse method and prospective error analysis, J. Geophys. Res., 113, D05305, doi:10.1029/2006JD008336.

Crisp, D., et al. (2004), The Orbiting Carbon Observatory (OCO) mission, Adv. Space Res., 34, 700-709, doi:10.1016/j.asr.2003.08.062.

Crisp, D., et al. (2012), The ACOS $\mathrm{X}_{\mathrm{CO}_{2}}$ retrieval algorithm, Part 2: Global $\mathrm{X}_{\mathrm{CO}}$ data characterization, Atmos. Meas. Tech. Discuss., 5, 1-60, doi:10.5194/amt-5-687-2012

de Rooij, W. A., and C. C. A. H. van der Stap (1984), Expansion of Mie scattering matrices in generalized spherical function, Astron. Astrophys., 131(2), 237-248.

Dufour, E., and F. M. Breon (2003), Spaceborne estimate of atmospheric $\mathrm{CO}_{2}$ column by use of the differential absorption method: Error analysis, Appl. Opt., 42, 3595-3609.

Eguchi, N., T. Yokota, and G. Inoue (2007), Characteristics of cirrus clouds from ICESat/GLAS observations, Geophys. Res. Lett., 34, L09810, doi:10.1029/2007GL029529.

Feng, L., P. I. Palmer, H. Boesch, and S. Dance (2009), Estimating surface $\mathrm{CO}_{2}$ fluxes from space-borne $\mathrm{CO}_{2}$ dry air mole fraction observations using an ensemble Kalman filter, Atmos. Chem. Phys., 9, 2619-2633, doi:10.5194/acp-9-2619-2009.
Feng, L., P. I. Palmer, Y. Yang, R. M. Yantosca, S. R. Kawa, J.-D. Paris, H. Matsueda, and T. Machida (2011), Evaluating a 3-D transport model of atmospheric $\mathrm{CO}_{2}$ using ground-based, aircraft, and space-borne data, Atmos. Chem. Phys., 11, 2789-2803, doi:10.5194/acp-11-2789-2011.

Frankenberg, C., T. Warneke, A. Butz, I. Aben, F. Hase, P. Spietz, and L. Brown (2008), Pressure broadening in the $2 \mathrm{n} 3$ band of methane and its implication on atmospheric retrievals, Atmos. Chem. Phys., 8, 5061-5075, doi:10.5194/acp-8-5061-2008.

Frankenberg, C., et al. (2011), New global observations of the terrestrial carbon cycle from GOSAT: Patterns of plant fluorescence with gross primary productivity, Geophys. Res. Lett., 38, L17706, doi:10.1029/ 2011GL048738.

Frankenberg, C., C. O’Dell, L. Guanter, and J. McDuffie (2012), Chlorophyll fluorescence remote sensing from space in scattering atmospheres: Implications for its retrieval and interferences with atmospheric $\mathrm{CO}_{2}$ retrievals, Atmos. Meas. Tech. Discuss., 5, 2487-2527, doi:10.5194 amtd-5-2487-2012.

Fraser, A., C. C. Miller, P. I. Palmer, N. M. Deutscher, N. B. Jones, and D. W. T. Griffith (2011), The Australian methane budget: Interpreting surface and train-borne measurements using a chemistry transport model, J. Geophys. Res., 116, D20306, doi:10.1029/2011JD015964.

GLOBALVIEW-CO2 (2011), Cooperative Atmospheric Data Integration Project - Carbon Dioxide [CD-ROM], NOAA ESRL, Boulder, Colo.

Gurney, K. R., et al. (2002), Towards robust regional estimates of $\mathrm{CO}_{2}$ sources and sinks using atmospheric transport models, Nature, 415, 626-630, doi:10.1038/415626a.

Houweling, S., F. M. Breon, I. Aben, C. Rodenbeck, M. Gloor, M. Heimann, and P. Ciais (2004), Inverse modeling of $\mathrm{CO}_{2}$ sources and sinks using satellite data: A synthetic inter-comparison of measurement techniques and their performance as a function of space and time, Atmos. Chem. Phys., 4, 523-538, doi:10.5194/acp-4-523-2004

Hungershoefer, K., F.-M. Bréon, P. Peylin, F. Chevallier, P. Rayner, A. Klonecki, S. Houweling, and J. Marshall (2010), Evaluation of various observing systems for the global monitoring of $\mathrm{CO}_{2}$ surface fluxes, Atmos Chem. Phys., 10, 10,503-10,520, doi:10.5194/acp-10-10503-2010.

Intergovernmental Panel on Climate Change (IPCC) (2001), Climate Change 2001: The Scientific Basis. Contribution of Working Group I to the Third Assessment Report of the Intergovernmental Panel on Climate Change (IPCC), edited by J. T. Houghton et al., Cambridge Univ. Press, Cambridge, U. K., doi:10.1256/004316502320517344.

Intergovernmental Panel on Climate Change (IPCC) (2007), Climate Change 2007: Working Group I: The Physical Science Basis. Contribution of Working Group I to the Fourth Assessment Report of the Intergovernmental Panel on Climate Change, edited by S. Solomon et al., Cambridge Univ. Press, Cambridge, U. K.

Jenouvrier, A., L. Daumont, L. Regalia-Jarlot, V. G. Tyuterev, M. Carleer, A. C. Vandaele, S. Mikhailenko, and S. Fally (2007), Fourier transform measurements of water vapor line parameters in the $4200-6600 \mathrm{~cm}^{-1}$ region, J. Quant. Spectrosc. Radiat. Transfer, 105(2), 326-355, doi:10.1016/j.jqsrt.2006.11.007.

Kahn, R., P. Banerjee, and D. McDonald (2001), Sensitivity of multiangle imaging to natural mixtures of aerosols over ocean, J. Geophys. Res. 106, 18,219-18,238, doi:10.1029/2000JD900497.

Kuang, Z., J. Margolis, G. Toon, D. Crisp, and Y. Yung (2002), Spaceborne measurements of atmospheric $\mathrm{CO}_{2}$ by high-resolution NIR spectrometry of reflected sunlight: An introductory study, Geophys. Res. Lett., 29(15), 1716, doi:10.1029/2001GL014298.

Kuze, A., H. Suto, M. Nakajima, and T. Hamazaki (2009), Thermal and near infrared sensor for carbon observation Fourier-transform spectrometer on the Greenhouse Gases Observing Satellite for greenhouse gases monitoring, Appl. Opt., 48(35), 6716-6733, doi:10.1364/AO.48.006716.

Masarie, K. A., and P. P. Tans (1995), Extension and integration of atmospheric carbon dioxide data into a globally consistent measurement record, J. Geophys. Res., 100, 11,593-11,610, doi:10.1029/95JD00859.

Messerschmidt, J., et al. (2011), Calibration of TCCON column-averaged $\mathrm{CO}_{2}$ : The first aircraft campaign over European TCCON sites, Atmos. Chem. Phys., 11, 10,765-10,777, doi:10.5194/acp-11-10765-2011.

Miller, C. E., et al. (2007), Precision requirements for space-based $\mathrm{X}_{C_{2}}$ data, J. Geophys. Res., 112, D10314, doi:10.1029/2006JD007659.

Mishchenko, M. I., and L. D. Travis (1998), Capabilities and limitations of a current Fortran implementation of the T-matrix method for randomly oriented, rotationally symmetric scatterers, J. Quant. Spectrosc. Radiat. Transfer, 60(3), 309-324, doi:10.1016/S0022-4073(98)00008-9.

Morino, I., et al. (2011), Preliminary validation of column-averaged volume mixing ratios of carbon dioxide and methane retrieved from GOSAT short-wavelength infrared spectra, Atmos. Meas. Tech., 4(6), 1061-1076, doi:10.5194/amt-4-1061-2011.

Natraj, V., and R. Spurr (2007), A fast linearized pseudo-spherical two orders of scattering model to account for polarization in vertically 
inhomogeneous scattering-absorbing media, J. Quant. Spectrosc. Radiat. Transfer, 107, 263-293, doi:10.1016/j.jqsrt.2007.02.011.

O'Dell, C. W. (2010), Acceleration of multiple-scattering, hyperspectral radiative transfer calculations via low-streams interpolation, J. Geophys. Res., 115, D10206, doi:10.1029/2009JD012803.

O'Dell, C. W., et al. (2012), The ACOS $\mathrm{CO}_{2}$ retrieval algorithm - Part 1: Description and validation against synthetic observations, Atmos. Meas. Tech., 5, 99-121, doi:10.5194/amtd-4-6097-2011.

Oshchepkov, S., A. Bril, and T. Yokota (2009), An improved photon path length probability density function-based radiative transfer model for space-based observation of greenhouse gases, J. Geophys. Res., 114, D19207, doi:10.1029/2009JD012116.

Oshchepkov, S., et al. (2012), Effects of atmospheric light scattering on spectroscopic observations of greenhouse gases from space: Validation of PPDF-based $\mathrm{CO}_{2}$ retrievals from GOSAT, J. Geophys. Res., 117, D12305, doi:10.1029/2012JD017505.

Palmer, P. I., L. Feng, and H. Boesch (2011), Spatial resolution of tropical terrestrial $\mathrm{CO}_{2}$ fluxes inferred using space-borne $\mathrm{CO}_{2}$ sampled in different Earth orbits: The role of spatial error correlations, Atmos. Meas. Tech. 4, 1995-2006, doi:10.5194/amtd-4-3251-2011.

Parker, R., et al. (2011), Methane observations from the Greenhouse Gases Observing SATellite: Comparison to ground-based TCCON data and model calculations, Geophys. Res. Lett., 38, L15807, doi:10.1029/ 2011GL047871.

Patra, P. K., et al. (2011), TransCom model simulations of $\mathrm{CH}_{4}$ and related species: Linking transport, surface flux and chemical loss with $\mathrm{CH}_{4}$ variability in the troposphere and lower stratosphere, Atmos. Chem. Phys. 11, 12,813-12,837, doi:10.5194/acp-11-12813-2011.

Pickett-Heaps, C. A., et al. (2011), Atmospheric $\mathrm{CO}_{2}$ inversion validation using vertical profile measurements: Analysis of four independent inversion models, J. Geophys. Res., 116, D12305, doi:10.1029/2010JD014887.

Randerson, J. T., M. V. Thompson, T. J. Conway, I. Y. Fung, and C. B. Field (1997), The contribution of terrestrial sources and sinks to trends in the seasonal cycle of atmospheric carbon dioxide, Global Biogeochem Cycles, 11, 535-560, doi:10.1029/97GB02268.

Rayner, P. J., and D. M. O'Brien (2001), The utility of remotely sensed $\mathrm{CO}_{2}$ concentration data in surface source inversions, Geophys. Res. Lett., 28(1), 175-178, doi:10.1029/2000GL011912.

Reuter, M., M. Buchwitz, O. Schneising, J. Heymann, H. Bovensmann, and J. P. Burrows (2010), A method for improved SCIAMACHY $\mathrm{CO}_{2}$ retrieval in the presence of optically thin clouds, Atmos. Meas. Tech., 3 , 209-232, doi:10.5194/amtd-2-2483-2009.

Rodgers, C. D. (2000), Inverse Methods for Atmospheric Sounding: Theory and Practise, Ser. Atmos. Oceanic Planet. Phys., vol. 3, World Sci., Hackensack, N. J.

Rodgers, C. D., and B. J. Connor (2003), Intercomparison of remote sounding instruments, J. Geophys. Res., 108(D3), 4116, doi:10.1029/ 2002JD002299.

Rothman, L. S., et al. (2009), The HITRAN 2008 molecular spectroscopic database, J. Quant. Spectrosc. Radiat. Transfer, 110(9-10), 533-572, doi:10.1016/j.jqsrt.2009.02.013
Schneising, O., M. Buchwitz, J. P. Burrows, H. Bovensmann, M. Reuter, J. Notholt, R. Macatangay, and T. Warneke (2008), Three years of greenhouse gas column-averaged dry air mole fractions retrieved from satellite - Part 1: Carbon dioxide, Atmos. Chem. Phys., 8, 3827-3853, doi:10.5194/acp-8-3827-2008.

Spurr, R. J. D., T. P. Kurosu, and K. V. Chance (2001), A linearized discrete ordinate radiative transfer model for atmospheric remote-sensing retrieval, J. Quant. Spectrosc. Radiat. Transfer, 68, 689-735, doi:10.1016/S00224073(00)00055-8.

Suto, H., A. Kuze, K. Shiomi, M. Nakajima, and T. Hamazaki (2011) Updated level-1 processing after two-years operation of TANSO-FTS, Proc. SPIE Int. Soc. Opt. Eng., 8154, 81541A, doi:10.1117/12.893405.

Takahashi, T., et al. (2009), Climatological mean and decadal change in surface ocean $\mathrm{pCO}_{2}$, and net sea-air $\mathrm{CO}_{2}$ flux over the global oceans, Deep Sea Res., Part II, 56(8-10), 554-577, doi:10.1016/j.dsr2.2008.12.009.

Taylor, T. E., C. W. O’Dell, D. M. O’Brien, N. Kikuchi, T. Yokota, T. Y. Nakajima, H. Ishida, D. Crisp, and T. Nakajima (2012), Comparison of cloud-screening methods applied to GOSAT near-infrared spectra, IEEE Trans. Geosci. Remote Sens., 50(1), 295-309, doi:10.1109/TGRS.2011. 2160270 .

Toth, R. (2005), Measurements of positions, strengths and self-broadened widths of $\mathrm{H}_{2} \mathrm{O}$ from 2900 to $8000 \mathrm{~cm}^{-1}$ : Line strength analysis of the 2nd triad bands, J. Quant. Spectrosc. Radiat. Transfer, 94(1), 51-107, doi:10.1016/j.jqsrt.2004.08.042

Toth, R., L. Brown, C. Miller, V. Malathy Devi, and D. Benner (2008), Spectroscopic database of $\mathrm{CO}_{2}$ line parameters: $4300-7000 \mathrm{~cm}^{-1}$, J. Quant. Spectrosc. Radiat. Transfer, 109(6), 906-921, doi:10.1016/ jqsit.2007.12.004.

Wunch, D., et al. (2010), Calibration of the Total Carbon Column Observing Network using aircraft profile data, Atmos. Meas. Tech., 3, 1351-1362, doi:10.5194/amt-3-1351-2010.

Wunch, D., G. C. Toon, J.-F. L. Blavier, R. A. Washenfelder, J. Notholt B. J. Connor, D. W. T. Griffith, V. Sherlock, and P. O. Wennberg (2011a), The total carbon column observing network, Philos. Trans. R. Soc. A, 369, 2087-2112, doi:10.1098/rsta.2010.0240.

Wunch, D., et al. (2011b), A method for evaluating bias in global measurements of $\mathrm{CO}_{2}$ total columns from space, Atmos. Chem. Phys., 11 12,317-12,337, doi:10.5194/acp-11-12317-2011

Yevich, R., and J. A. Logan (2003), An assessment of biofuel use and burning of agricultural waste in the developing world, Global Biogeochem Cycles, 17(4), 1095, doi:10.1029/2002GB001952.

Yokota, T., Y. Yoshida, N. Eguchi, Y. Ota, T. Tanaka, H. Watanabe, and S. Maksyutov (2009), Global concentrations of $\mathrm{CO}_{2}$ and $\mathrm{CH}_{4}$ retrieved from GOSAT: First preliminary results, SOLA, 5, 160-163, doi:10.2151/ sola.2009-041.

Yoshida, Y., Y. Ota, N. Eguchi, N. Kikuchi, K. Nobuta, H. Tran, I. Morino, and T. Yokota (2011), Retrieval algorithm for $\mathrm{CO}_{2}$ and $\mathrm{CH}_{4}$ column abundances from short-wavelength infrared spectral observations by the greenhouse gases observing satellite, Atmos. Meas. Tech., 4, 717-734, doi:10.5194/amt-4-717-2011. 